\title{
Reconciliation of measurements of hygroscopic growth and critical supersaturation of aerosol particles in central Germany
}

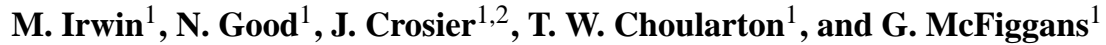 \\ ${ }^{1}$ School of Earth, Atmospheric and Environmental Sciences, University of Manchester, Manchester, UK \\ ${ }^{2}$ National Centre for Atmospheric Science, University of Manchester, Manchester, UK
}

Received: 31 May 2010 - Published in Atmos. Chem. Phys. Discuss.: 12 July 2010

Revised: 28 November 2010 - Accepted: 6 December 2010 - Published: 10 December 2010

\begin{abstract}
Aerosol physical, chemical and hygroscopic properties were measured in a range of airmasses during COPS (Convective and Orographically-induced Precipitation Study) ground-based in June and July of 2007 at the Hornisgrinde mountain site in the Black Forest, Southwest Germany. Non-refractory aerosol composition was measured with an Aerosol Mass Spectrometer, simultaneous to hygroscopic growth factors at $86 \%$ relative humidity and $\mathrm{CCN}$ activity measurements for particles of dry $(<20 \%)$ diameters 27 to $217 \mathrm{~nm}$, with particle water uptake exhibiting substantial variability with time and with particle size.

Variability in the measurements of hygroscopic growth factor and critical supersaturation for particles of similar sizes indicates significant compositional impact on particle water affinity. Critical supersaturation prediction using a single parameter hygroscopicity approximation derived from measured HTDMA mean growth factors deviate, beyond measurement uncertainties, from critical supersaturations derived from $\mathrm{CCN}$ measurements. These led to differences averaging around $35 \%$ in the number of $\mathrm{CCN}\left(N_{\mathrm{CCN}}\right)$ for the most reliable measurements depending on averaging methodology, often very much larger for individual time periods. This indicates aspects of water uptake behaviour unresolved in this experiment by the single parameter representation which, depending on its origin, may have important consequences on its generalised use.
\end{abstract}

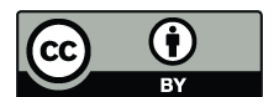

Correspondence to: G. McFiggans (gordon.mcfiggans@manchester.ac.uk)

\section{Introduction}

Atmospheric aerosol plays a key role in a number of important climate processes, commonly classified into direct effects (scattering and absorbing radiation; McCormick and Ludwig, 1967; Haywood and Boucher, 2000) and indirect effects (radiative effects that result from modifying the reflectivity, abundance, persistence and other cloud properties). The Intergovernmental Panel on Climate Change (IPCC) Fourth Assessment Report has attributed the largest uncertainty in radiative forcing to that of the aerosol indirect effect (Forster et al., 2007). The first indirect effect, the cloud albedo effect, occurs because differences in the number of cloud condensation nuclei $\left(N_{\mathrm{CCN}}\right)$ alter the reflectivity of clouds (Twomey, 1977). Aerosol particles also have effects on cloud longevity and the initiation or delay of precipitation through increased $N_{\mathrm{CCN}}$, which are some of the secondary indirect effects on climate (Albrecht, 1989; Lohmann and Feichter, 2005; Andreae and Rosenfeld, 2008). Uncertainty in $N_{\mathrm{CCN}}$ is central to the uncertainty in the aerosol indirect effects.

The ability for a particle to act as a $\mathrm{CCN}$ depends on its size and composition. Particles of a dry diameter less than $40 \mathrm{~nm}$ are unlikely to activate into cloud droplets regardless of composition and sufficiently large particles will most probably contain enough soluble material to activate under all reasonable atmospheric supersaturations (McFiggans et al., 2006). If a particle's composition is known, then its water uptake at equilibrium can be modelled using the Köhler equation (Köhler, 1936; Rogers and Yau, 1989; Pruppacher and Klett, 1997; Seinfeld and Pandis, 1998) based on physicochemical properties of the solute:

Published by Copernicus Publications on behalf of the European Geosciences Union. 
$S=a_{\mathrm{w}} \exp K_{\mathrm{e}}$

where $S$ is the saturation ratio $(=\mathrm{RH} / 100), a_{\mathrm{w}}$ is the water activity or Raoult term, and $K_{\mathrm{e}}$ is the Kelvin term.

The Köhler equation can be envisaged as the competition between two effects, namely the Raoult effect and Kelvin effect. The Raoult effect is defined by the water activity and drawing water into the growing droplet by virtue of the soluble material therein. The Kelvin effect is defined by the resistance to growth resulting from the increased saturation vapour pressure of water with increasing curvature of smaller particles by virtue of the energy associated with the creation of the droplet surface. The Köhler equation is dominated by the water activity when significantly below saturation and the Kelvin term increases in importance approaching the point of activation. The relative importance of the terms in the Köhler equation is explored systematically in Wex et al. (2008).

The atmospheric aerosol is comprised of substantial amounts of organic material (Kanakidou et al., 2005; Hallquist et al., 2009), which may suppress surface tension (Facchini et al., 2000; McFiggans et al., 2005, 2006; Weingartner et al., 2004). Since the surface tension enters into the Köhler equation through the Kelvin term and it is known that organic components may reduce the surface tension of their aqueous solutions, it has been assumed that organic components may play a role in determining cloud activation (e.g. Novakov and Penner, 1993; Saxena et al., 1995; Shulman et al., 1996; Abdul-Razzak and Ghan, 2004). A change in surface tension would play a more important role as the saturation ratio increases (Wex et al., 2008), thus it has been argued that the incorporation of organic material into existing inorganic particles may substantially reduce the supersaturation required to activate an aerosol particle into a cloud droplet (its critical supersaturation, $S_{\mathrm{c}}$ ). Such an effect would result in an increase in the number of $\mathrm{CCN}$ by impacting on the Kelvin term, whilst not significantly influencing subsaturated growth factor through impacts on the number of soluble molecules, affecting the Raoult term. However, bulk to surface partitioning has recently been postulated as occurring within a more detailed description of the surface chemistry which can increase the critical supersaturation required for activation by changing concentration gradients approaching the surface (Sorjamaa et al., 2004; Kokkola et al., 2006; Topping et al., 2007) acting to offset the reduction in $S_{\mathrm{c}}$ predicted to result from reduced surface tension.

A current challenge is to demonstrate the quantitative understanding of atmospheric aerosol behaviour under sub- and supersaturated conditions and the relationship between the two regimes. Multiple field studies from around the world utilising a variety of modelling techniques have compared sub- and supersaturated measurements and model predictions (e.g. Broekhuizen et al., 2006 and references to CCN closure studies in McFiggans et al., 2006 and e.g. Medina et al., 2007; Petters and Kreidenweis, 2007, and references therein) with varying degrees of success. The latter refer- ence presented the $\kappa$-Köhler model, making use of a single parameter $\kappa$ to describe particle hygroscopicity at any humidity. This approach can demonstrably reconcile sub- and supersaturated behaviour of inorganic salts such as sodium chloride within experimental uncertainty, and the use of $\kappa$ to describe the hygroscopicity of ambient aerosol populations has been explored previously (Andreae and Rosenfeld, 2008; Gunthe et al., 2009).

In this study we use the $\kappa$-Köhler model to interpret data from both sub- and supersaturated regimes measured at a continental forest site with strong topographical and convective influences on cloud formation, aiming to reconcile particle water uptake in the two regimes.

\section{Experimental methodology}

\subsection{Sampling Site and measurement platform}

Measurements were conducted from 24 June to 18 July 2008 as part of the Convective and Orographically forced Precipitation Study (COPS) at the Hornisgrinde SuperSite $\left(48^{\circ} 36^{\prime} 0^{\prime \prime} \mathrm{N}, 8^{\circ} 12^{\prime} 0^{\prime \prime} \mathrm{E}\right)$, which is located in the Western Black Forest in Germany. The Hornisgrinde Mountain is at a height of $1164 \mathrm{~m}$ a.b.s.l. and the moorland area at the summit of the Hornisgrinde is a nature reserve with pedestrian access and little vehicle activity. Further details of the measurement site and the COPS programme are presented in detail by Wulfmeyer et al. (2008).

Air was drawn down a $40 \mathrm{~mm}$ bore, $3 \mathrm{~m}$ high stainless steel stack at a flow rate of $351 / \mathrm{min}$, through a cyclone impactor with a $4 \mu \mathrm{m}$ cut-off, and then into the container to the instrumentation which, excepting the water uptake measurement instrumentation outlined in Sects. 2.2 and 2.3, is described in more detail by Jones et al. (2010).

\subsection{Sub-saturated water uptake measurement}

A Hygroscopicity Tandem Differential Mobility Analyser (HTDMA; Cubison et al., 2005; Gysel et al., 2007) was used to measure the hygroscopic growth factor distributions at $86 \%$ relative humidity $(\mathrm{RH})$ of particles with dry diameters $\left(D_{0}\right) ; 27,43,85,127,169,211$ and $254 \mathrm{~nm}$. The hygroscopic growth factor of a particle is defined as the ratio of wet $(86 \%$ $\mathrm{RH})$ to dry $(<20 \% \mathrm{RH})$ particle diameter. To ensure the HTDMA instrument was measuring reliably, the instrument was calibrated as described in Good et al. (2010a). Briefly, the laminar flow elements and pressure transducers controlling flow through the Differential Mobility Analysers (DMAs) were calibrated using a bubble flowmeter and the DMAs were size-calibrated using NIST-traceable polystyrene latex spheres (PSLs) as outlined by Good et al. (2010a). The RH and temperature sensors within the instrument were calibrated and continuously referenced against a dew point hydrometer (Cubison et al., 2005). Dry ( $\mathrm{RH} \leq 20 \%)$ scans were performed at weekly intervals to ensure that both the DMAs were in agreement, to monitor the width of the DMA transfer functions, to measure the offset between the two 
DMAs as well as any temporal trend (Gysel et al., 2009; Good et al., 2010a). The HTDMA system was calibrated with dried, charge-neutralised $150 \mathrm{~nm}$ ammonium sulphate and sodium chloride ( $\geq 99.5 \%$, Sigma Aldrich) such that the RH of the second DMA was increased slightly beyond the measurement range (to typically greater than 90\% RH). Both deliquescence and effloresced points for both salts are measured by the HTDMA and verified against the ADDEM model (Topping et al., 2005).

The first DMA was used to select dry particle size with dry sheath air and a residence time of $\sim 60 \mathrm{~s}$ was included between the humidifier and the second DMA (Cubison et al., 2005; Gysel et al., 2007). The second DMA was operated with both sheath and aerosol flows at a target RH of $86 \%$, as due to unforeseen circumstances the instrument struggled to reach $90 \%$ RH whilst sampling ambient aerosol, and the decision was made to sample at a lower RH with greater stability. The target of $86 \% \mathrm{RH}$ was reached for the majority of the experiment with variability between $84-88 \%$ RH. The second DMA voltage (and thus mobility diameter) was stepped through each $D_{0}$ to measure the raw particle diameter growth factor distribution. These raw data were inverted to account for the HTDMA instrument function using the TDMAinv algorithm along with the associated analysis and quality assurance procedures described by Gysel et al. (2009).

Further to inversion, data measured between $84 \%-88 \%$ RH were corrected to $86 \%$ RH using Eq. (S1) in the Supplement, and an error simulation showing the sensitivity of the inversion result to small changes in measurement was performed as described by Gysel et al. (2009). The results of the error simulation and the propagation of measurement uncertainty as standard errors are described in Sect. 1.1 of the Supplement. From the analysis and error propagation, the mean of the particle growth factor probability distribution $(p(\mathrm{GF})$; the probability distribution of the aerosol particle having a specific growth factor) becomes the corrected mean growth factor, $\overline{\mathrm{GF}}_{D_{0}, \mathrm{RH}, \mathrm{c}}$.

\subsection{Droplet activation measurement}

A Droplet Measurement Technologies (DMT) Cloud Condensation Nucleus counter ( $\mathrm{CCNc}$; Roberts and Nenes, 2005) was used to probe the activation behaviour of the sampled particles. The $\mathrm{CCNc}$ instrumental configuration was alternated between sampling poly-disperse and monodisperse aerosol. To generate a monodisperse aerosol, dried $(\mathrm{RH}<20 \%)$ polydisperse aerosol was charge equilibrated then size selected in a DMA. This monodisperse aerosol was then split between the CCNc and a 3010 TSI Condensation Particle Counter (CPC) with the sample line lengths from the DMA to the CPC inlet and top of the CCNc column matched in order to ensure line losses were equal. The DMA operated at an aerosol flow rate of $1 \mathrm{Lmin}^{-1}$ (10:1 with sheath flow), the $\mathrm{CCNc}$ operated at $0.5 \mathrm{Lmin}^{-1}$, the $\mathrm{CPC}$ at $1 \mathrm{Lmin}^{-1}$ with $0.5 \mathrm{Lmin}^{-1}$ from the DMA and $0.5 \mathrm{Lmin}^{-1}$ from a filtered air supply. All sample flows were ensured to be the same and were calibrated and checked daily with a bubble flow meter. For each mobility-selected size, the ratio of $\mathrm{CCN}$ to CPC concentration defines the activated fraction at a given supersaturation. Particles just below their critical supersaturation may have a large unactivated equilibrium size that can be of the same order as activated droplets $(\approx 1 \mu \mathrm{m}$, Lance et al., 2006) and particles were judged to have activated when detected by the OPC in the CCNc at diameters above $1 \mu \mathrm{m}$. The fraction of the particles at a given supersaturation $(S)$ and dry diameter $\left(D_{0}\right)$ that have activated into cloud droplets is defined as $F_{\mathrm{A}}\left(S, D_{0}\right)=N\left(S, D_{0}\right) / N\left(D_{0}\right)$ where $N\left(S, D_{0}\right)$ is the number of activated particles counted by the $\mathrm{CCNc}$ and $N\left(D_{0}\right)$ is the number of condensation nuclei $(\mathrm{CN})$.

Perfectly monodisperse internally mixed particles would all activate at a single discrete supersaturation such that $100 \%$ of the particles would be unactivated at an infinitesimally lower supersaturation, but activated at an infinitesimally higher value. In reality, the monodisperse selection will be of finite dispersion with broadening defined by the DMA transfer function. In addition, as found by Rose et al. (2008) there is an indeterminate contribution to the "system transfer function" such that deviation in the observed CCN spectrum from a step change in the activated fraction does not result from the ideal transfer function of the DMA alone.

Assuming that the DMA transfer function is symmetrical about the selected dry mobility, the supersaturation at which $50 \%$ of the particles have activated into cloud droplets for a given dry diameter, was directly interpreted as representing the critical supersaturation for activation, denoted $S_{\mathrm{c}, D_{0}}$ and derived by fitting a sigmoidal function to $F_{\mathrm{A}}\left(S, D_{0}\right)$ vs. $S_{\text {set }}$, as described in Sect. 1.2 in the Supplement, and hereafter referred to as S-step analysis. Variations in the hygroscopicity of particles of the same $D_{0}$ may lead to further spectral broadening, affecting the interpretation of $S_{\mathrm{c}, D_{0}}$. The impacts of such deviations from an internally-mixed particle population is discussed later. In addition to deriving particle critical supersaturation through $S$-step analysis, fitting the sigmoid function to a plot of $F_{\mathrm{A}}\left(S, D_{0}\right)$ vs. $D_{0}$ defines Dstep analysis, from which the diameter at which $50 \%$ of the particles activated into cloud droplets was derived at each supersaturation; $D_{50, S}$. The sigmoidal function is identical for both S-Step and D-step analyses, described in Sect. 1.2 in the Supplement.

The DMA supplying the CCNc performed a full cycle of sequential steps of values of $D_{0}$ every $7 \mathrm{~min}$, with a $3 \mathrm{~min}$ settling period before each 7 min sequence (to allow temperatures in the CCNc column to stabilise), resulting in $10 \mathrm{~min}$ size distributions. Simultaneously, the $\mathrm{CCNc}$ would step through 5 different values of $S_{\text {set }}$ every hour, remaining at each supersaturation for $10 \mathrm{~min}$, with lowest supersaturation scan repeated twice at the beginning of each hour to allow for the temperature to stabilise down the column. Therefore, every $10 \mathrm{~min}$, a full cycle of $D_{0}$ steps were performed and every hour, a full cycle of $S_{\text {set }}$ steps were performed. 
The benefit of S-step analysis is that the critical supersaturation for multiple dry diameters is measured on an hourly basis. However, D-step analysis typically has a smaller associated fitting error resulting from the increase in the number of data points used in each sigmoidal fit (20 $D_{0}$ for each of the five supersaturations; see Sect. 1.2 in the Supplement). The single hygroscopicity parameter $\kappa$ may be derived from either S-step or D-step analysis. However, the error associated with the calculation of $\kappa$ cannot be propagated as the the $\kappa$-model cannot be solved numerically or analytically, and as such the uncertainty in $\kappa$ is simply propagated through as a standard error from the sigmoidal fit, resulting in maximum and minimum values of $\kappa$, described in Sect. 2.5. The number of $\mathrm{CCN}\left(N_{\mathrm{CCN}}\right)$ for a given dry diameter and supersaturation can be calculated from both S-step and D-step approaches and the aerosol number-size distributions as described in Sect. 3.6.

CCN instrument calibration involved the sampling of nebulised, dried, charge-equilibrated, and size-selected ammonium sulphate ( $\geq 99.5 \%$, Sigma Aldrich) and sodium chloride ( $\geq 99.5 \%$, Sigma Aldrich) aerosol particles with a TSI $3010 \mathrm{CPC}$ and the CCNc. The measured $S_{\mathrm{c}}$ was plotted against the predicted $S_{\mathrm{c}}$ of ammonium sulphate particles of the same dry diameter as calculated using the ionic interaction model within the Aerosol Diameter Dependent Equilibrium Model (ADDEM; Topping et al., 2005). A $\Delta T$ dependent calibration factor was applied such that the calibrated supersaturation setpoints were $0.11 \%, 0.17 \%, 0.32 \%$, $0.50 \%$ and $0.80 \%$ (the supersaturation range was increased from $0.11 \%, 0.17 \%, 0.28 \%, 0.35 \%$ and $0.65 \%$ after the first week, 25 June-3 July, after reviewing the aerosol activation behaviour).

The number fraction of particles with multiple charges at $F_{\mathrm{A}}\left(S, D_{0}\right)=0.5$ of the calibration aerosol were found to be negligible due to the shape of the distribution. Nevertheless, the dataset was corrected for the effects of multiply charged particles in standard DMPS procedure, using the charging probability coefficients found by Wiedensohler (1987) as reported by Good et al. (2010a). As the container was air conditioned to $20^{\circ} \mathrm{C} \pm 2{ }^{\circ} \mathrm{C}$, the set point supersaturations corresponded to a near-constant $\Delta T$ and thus absolute $T$, ensuring validity of the calibration. In addition to calibrations, uncertainty in the measurements have been propagated through the data analysis as described in previously, in the Supplement. Hourly switching of the DMA-CCNc instrumentation between polydisperse and monodisperse operation continued throughout the project, as the DMPS made use of two DMA columns, compared to the sole DMA used in the DMA-CCNc configuration. When the $\mathrm{CCNc}$ was running in poly-disperse mode, the CPC was used in the Differential Mobility Particle Sizer (DMPS; Williams et al., 2007) instrument. During monodisperse operation, the DMA supplied the $\mathrm{CCNc}$ and $\mathrm{CPC}$ as outlined above. Only results from this latter mode of operation are presented here.
A more complete description of the calibration, quality assurance procedures carried out for the two instruments is presented by Good et al. (2010a) and additional information on the error propagation can be found in the Supplement.

\subsection{Aerosol composition}

A High-Resolution Time-of-Flight Aerosol Mass Spectrometer (HR-ToF-AMS, Aerodyne Research Inc.) was used to probe non-refractory aerosol particle composition (DeCarlo et al., 2006). The instrument was operated with a heater temperature of approximately $550^{\circ} \mathrm{C}$ and is capable of measuring particles from $40 \mathrm{~nm}-700 \mathrm{~nm}$ vacuum aerodynamic diameter (DeCarlo et al., 2004). The mass size distribution of the aerosol particles was measured in particle mode. The collection efficiency used for the COPS data was 0.5 , which is consistent with results from laboratory (Matthew et al., 2008) resulting in broad agreement with the integrated submicron volume time series from the DMPS (i.e. within $20 \%$ using an organic density of $1.4 \mathrm{gm}^{-3}$ ).

\subsection{Predicting $S_{\mathrm{c}}$ from measured HTDMA GF}

The $\kappa$-Köhler model represents water activity $\left(a_{\mathrm{w}}\right)$ in terms of a constant $(\kappa)$ within the primitive Köhler equation (Eq. 1) assuming a constant value for surface tension within the kelvin term:

$$
S=\frac{D^{3}-D_{0}^{3}}{D^{3}-D_{0}^{3}(1-\kappa)} \exp \left(\frac{4 \sigma_{\mathrm{w}} M_{\mathrm{w}}}{R T \rho_{\mathrm{w}} D}\right)
$$

Where $D$ is the droplet diameter at the given RH, $D_{0}$ is dry particle diameter, $\sigma_{\mathrm{w}}$ is the surface tension of water, $M_{\mathrm{w}}$ is the molecular weight of water, $R$ is the universal gas constant, $T$ is the droplet temperature and $\rho_{\mathrm{w}}$ is the density of water.

To examine the applicability of the $\kappa$-Köhler approach taken by Petters and Kreidenweis (2007), $\kappa$ is derived from measured HTDMA-determined values of the hygroscopic diameter growth factor. Substituting $\mathrm{GF}_{\mathrm{D}_{0}, \mathrm{RH}}$ into Eq. (2), the $\kappa$-Köhler equation for a defined RH becomes:

$$
\mathrm{RH}=\frac{\mathrm{GF}_{D_{0}, \mathrm{RH}}^{3}-1}{\mathrm{GF}_{D_{0}, \mathrm{RH}}^{3}-(1-\kappa)} \exp \left(\frac{4 \sigma_{\mathrm{w}} M_{\mathrm{w}}}{R T \rho_{\mathrm{w}} D_{0} \mathrm{GF}_{D_{0}, \mathrm{RH}}}\right)
$$

The critical supersaturation predicted from the HTDMA, denoted $S_{\mathrm{c}, \mathrm{GF}}$, is predicted for a given droplet diameter using Eq. (3) with $\kappa_{\mathrm{GF}}$ (i.e. $\kappa$ derived from HTDMA measurements of hygroscopic Growth Factor) and incrementally increasing the growth factor until the relative humidity starts to decrease. As with traditional Köhler theory, the maximum in $S$ for a given size and composition (expressed by $\kappa$ ) determines $S_{\mathrm{c}}$ for activation to a cloud droplet (Petters et al., 2007).

\subsection{Error analysis}

In order to investigate whether the sub- and supersaturated water uptake behaviour can be reconciled within the 
measurement uncertainty, it is necessary to propagate the errors associated with each step in the analysis into each level of data product. A description of the uncertainty analysis and error propagation is provided in Sects. 1.1-1.3.3 in the Supplement.

Briefly, the measurements of both the CCNc and HTDMA have been broken down into primary and secondary data quantities, with the measurement uncertainty at each stage quantified as standard error. Equation (S4) in the Supplement shows the fitting function used to derive $S_{\mathrm{c}, D_{0}}$ and $D_{50, \mathrm{~s}}$. The function outputs a standard error, which is used to calculate maximum and minimum values of $S_{\mathrm{c}, D_{0}}$ and $D_{50, \mathrm{~S}}$. Similarly, the error defined by Eq. (S3) in the Supplement defines the standard error in $\mathrm{GF}_{D_{0}, \mathrm{RH}}$, providing a maximum and minimum $\mathrm{GF}_{D_{0}, \mathrm{RH}}$. These standard errors have been propagated through to higher order data products in order to better interpret the results of any comparison or the conclusions drawn.

\section{Results and analysis}

\subsection{Meteorological conditions}

For the majority of the experiment, the wind originated from west of southwest, flowing up the valley (see Fig. S2 in the Supplement). Throughout the experiment the measurement site was frequently within cloud, with ambient RH sensors saturating at $100 \%$ (Fig. S3 in the Supplement). Nocloud conditions often resulted from cloud base rising well above the measurement platform. The beginning of the measurement period (24 June-28 June) was characterised by cloud cover and some rainfall. The period of 29 June-2 July was mostly clear, with a distinct cloud event on the 30 June. The site was in cloud from 2-6 July, and again from 9-14 July. The final days of the measurement were characterised by clear, sunny days and low RH. Cloudy and no-cloud sampling periods were distinguished according to aerosol number concentrations as measured by a GRIMM Optical Particle Counter $(0.3 \mu \mathrm{m} \leq D \leq 20 \mu \mathrm{m}$ in conjunction with ambient RH data (GRIMM concentration $\leq 100 \mathrm{~L}^{-1}$ and $\mathrm{RH} \geq 95 \%$ ). These periods have been broadly approximated for contiguous representation and are described in Table 1. "Cloud periods" are denoted "CP" and "No-cloud" periods denoted "NC". Jones et al. (2010) have further detailed the meteorological conditions with the use of cloud camera data for their analysis.

During cloud periods, accumulation mode particle concentrations were low. This would be expected because of the activation of particles larger than the threshold dry size for activation forming droplets larger than the inlet cyclone cut of $4 \mu \mathrm{m}$. There were periods when high concentrations of particles $\left(1000 \mathrm{~cm}^{-3}\right)$ of $D_{0} \leq 20 \mathrm{~nm}$ were observed in both cloudy and no-cloud periods. Each no-cloud period was characterised by high concentrations of particles with
Table 1. Time and date for "cloud periods" (CP) and "no-cloud" (NC) periods as defined by RH and GRIMM measurements, and the Organic:Sulphate ratio for each period.

\begin{tabular}{lccc}
\hline Name & Start & End & Org:Sulphate \\
\hline CP1 & $25 / 06 / 200712: 00$ & $28 / 06 / 200716: 00$ & 2.251 \\
NC1 & $28 / 06 / 200716: 00$ & $02 / 07 / 200722: 00$ & 2.491 \\
CP2 & $02 / 07 / 200722: 00$ & $06 / 07 / 200715: 00$ & 2.522 \\
NC2 & $06 / 07 / 200715: 00$ & $08 / 07 / 200715: 00$ & 2.903 \\
CP3 & $08 / 07 / 200715: 00$ & $13 / 07 / 200711: 00$ & 3.635 \\
NC3 & $13 / 07 / 200711: 00$ & $18 / 07 / 200711: 30$ & 5.522 \\
CP4 & $18 / 07 / 200711: 30$ & $22 / 07 / 200713: 00$ & 2.830 \\
NC4 & $22 / 07 / 200713: 00$ & $23 / 07 / 200716: 00$ & 1.346 \\
\hline
\end{tabular}

$D_{0} \geq 30 \mathrm{~nm}$ a matter of hours after the RH dropped to below $80 \%$, with the distribution exhibiting apparent growth over the course of the day to an average $D_{0}$ of $100 \mathrm{~nm}$ (Fig. S3 in the Supplement). It is apparent that there was a significant dynamical evolution of the observed aerosol throughout the experiment.

\subsection{Aerosol composition}

The organic:sulphate mass ratio, as diagnosed from the HRToF-AMS, averaged 3:1 over the course of the project, with significant variability (see Fig. S3 in the Supplement). The organic:sulphate ratio tracks the organic:inorganic ratio well, with the majority of the variation in the organic:inorganic ratio coming from the variation in the sulphate component. Cloud periods are characterised by low accumulation mode number concentrations and lower mean organic:sulphate ratio (largely driven by enhanced sulphate loading), primarily seen in the second and fifth cloud periods, CP2 and CP5. A significant deviation from the mean was observed during the third no-cloud period, NC3, during which the organic:sulphate ratio was highly variable with peak ratio in excess of $8: 1$ and minima around 1:1. This highly variable period was followed by a more quiescent period and a reduction to the campaign mean ratio of 3:1 from the 17 July onwards. It should be noted that the meteorological influences on the aerosol composition were complex. All things being equal, one might expect sulphate aerosol to be preferentially scavenged by cloud and hence the organic to sulphate ratio to be enhanced in interstitial aerosol particles sampled under cloudy conditions. This was not clearly observed during COPS and the organic to sulphate ratio was frequently enhanced during no-cloud conditions. This was particularly noticeable during NC3. Prior to NC3, the cloud had been clearly advective and large-scale, with the possibility of large-scale in-cloud sulphate production leading to comparatively low organic:sulphate ratio. In contrast, the temperature (shown in the top panel of Fig. S3 in the Supplement) from this period onwards was warmer than before and the clearsky conditions were conducive to biogenic organic aerosol 


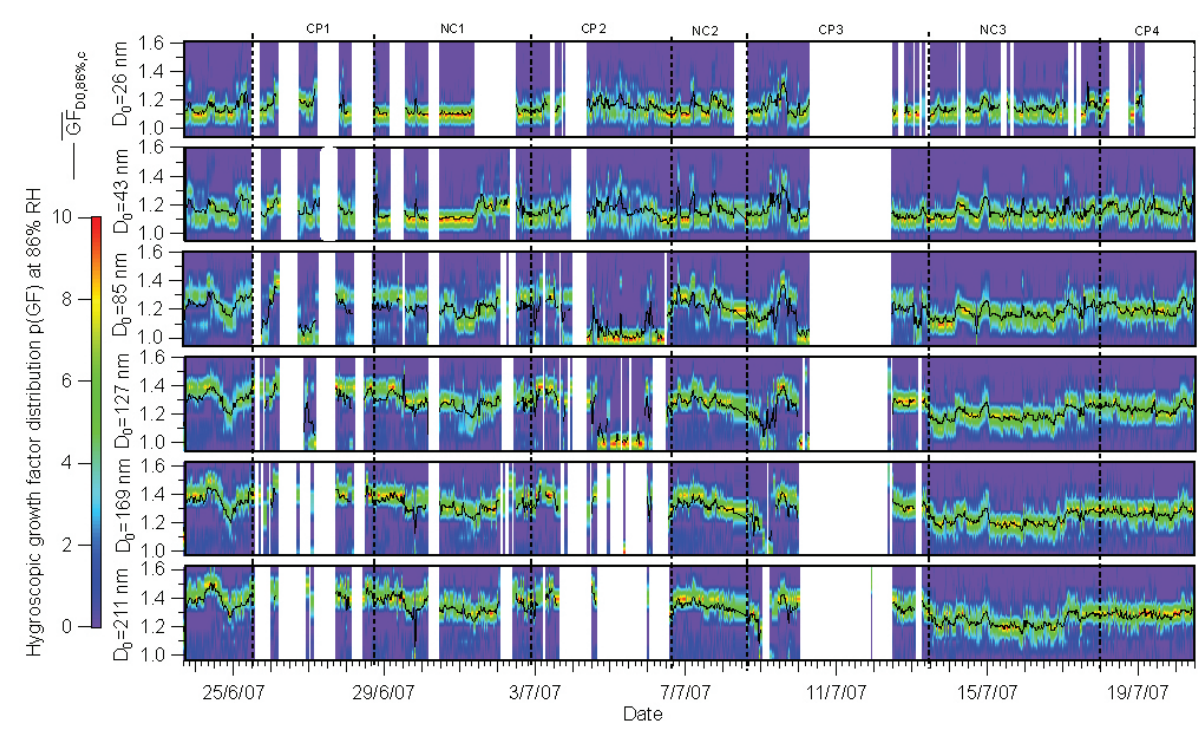

Fig. 1. Measured HTDMA hygroscopic growth factor probability distribution, $p(\mathrm{GF})$, as a function of time. The HTDMA growth factor

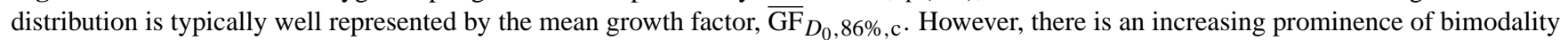
seen with an increase of size (see Fig. S6 in the Supplement).

formation that may have led to the increased organic:sulphate ratio (Jones et al., 2010).

The AMS cannot detect refractory components and such there are no measurements of dust, black carbon or sea-salt. Variations in any of these components would alter particulate composition and thus hygroscopicity with less hygroscopic components such as dust and black carbon and more hygroscopic components such as sea-salt influencing particle growth factor and critical supersaturation for given dry diameters, though the AMS cannot be used to probe the magnitude of each component. Black carbon was measured by a Multi-Angle Absorption Photometer (MAAP), and analysis of the data showed no distinct correlation between the measured amounts of $\mathrm{BC}$ and aerosol hygroscopicity and derived products such as $\kappa$ from HTDMA or CCNc as there was too little $\mathrm{BC}$ measured to affect the hygroscopic growth factor distrubutions. Dust and seasalt composition were not directly measured (though dust can be inferred from OPC measurements, aerosol hygroscopicity did not change greatly with the magnitude of the aerosol coarse mode and sea-salt is unlikely important in the COPS region). Aerosol composition during COPS is further discussed by Jones et al. (2010).

\subsection{Hygroscopic behaviour in the sub-saturated regime}

Growth factor probability densities were measured as described in Sect. 2.2 and are shown in Fig. 1 with a time resolution of $1 \mathrm{~h}$. For the majority of the measurement period a strong influence of particle size on hygroscopic growth is observed with the mean hygroscopic growth factor $\left(\overline{\mathrm{GF}}_{D_{0}, \mathrm{RH}, \mathrm{c}}\right)$ increasing from an average of 1.15 at $26 \mathrm{~nm}$ to 1.35 at $211 \mathrm{~nm}$. For the majority of the experiment, the mean growth factor represents well the modal growth factor for each measured size, though at times there is increased bimodality at dry diameters greater than $127 \mathrm{~nm}$. At all sizes, there is a fraction of the particles with low hygroscopicity (growth factor of $\sim 1.15$, similar to the mean seen at the lowest dry diameter, $D_{0}=26 \mathrm{~nm}$ ) though with considerably reduced relative contribution at larger sizes. When the concentrations of the less hygroscopic mode are higher ( $\mathrm{NC1}, \mathrm{NC} 2, \mathrm{CP} 3)$ the mean growth factor is reduced by up to 0.05 from the peak in the $p(\mathrm{GF})$, invariably found in the main, more hygroscopic mode.

The aerosol sampled during cloudy periods were, somewhat counter-intuitively, characterised by a low organic:sulphate ratio (as mentioned in Sect. 3.2 above), and this increase in relative sulphate is consistent with the slightly higher mean growth factors during these periods. Out of cloud mean growth factors tend to be lower in comparison, consistent with the increased mass fraction of organics, with a typical organic:sulphate ratio of $\geq 4: 1$.

\subsection{Measurements of cloud activation behaviour}

The fraction of aerosol activated, $F_{\mathrm{A}}\left(S, D_{0}\right)$, typically increases with both dry diameter and supersaturation as shown in Fig. 2. Towards the latter part of the first half of the experiment, it was noted that the supersaturation settings $S_{\text {set }}$ of $0.65 \%$ was not activating all of the aerosol size distribution. The measurement range was increased to a ceiling of $S_{\mathrm{set}}=0.80 \%$ as to improve the derivation of $S_{\mathrm{c}, D_{0}}$ for $D_{0}$ below $100 \mathrm{~nm}$. At the lowest supersaturation $(0.11 \%)$ only sizes with $D_{0}$ over $200 \mathrm{~nm}$ activate for the majority of the measurement period. As is expected, $F_{\mathrm{A}}\left(S, D_{0}\right)$ increases with 


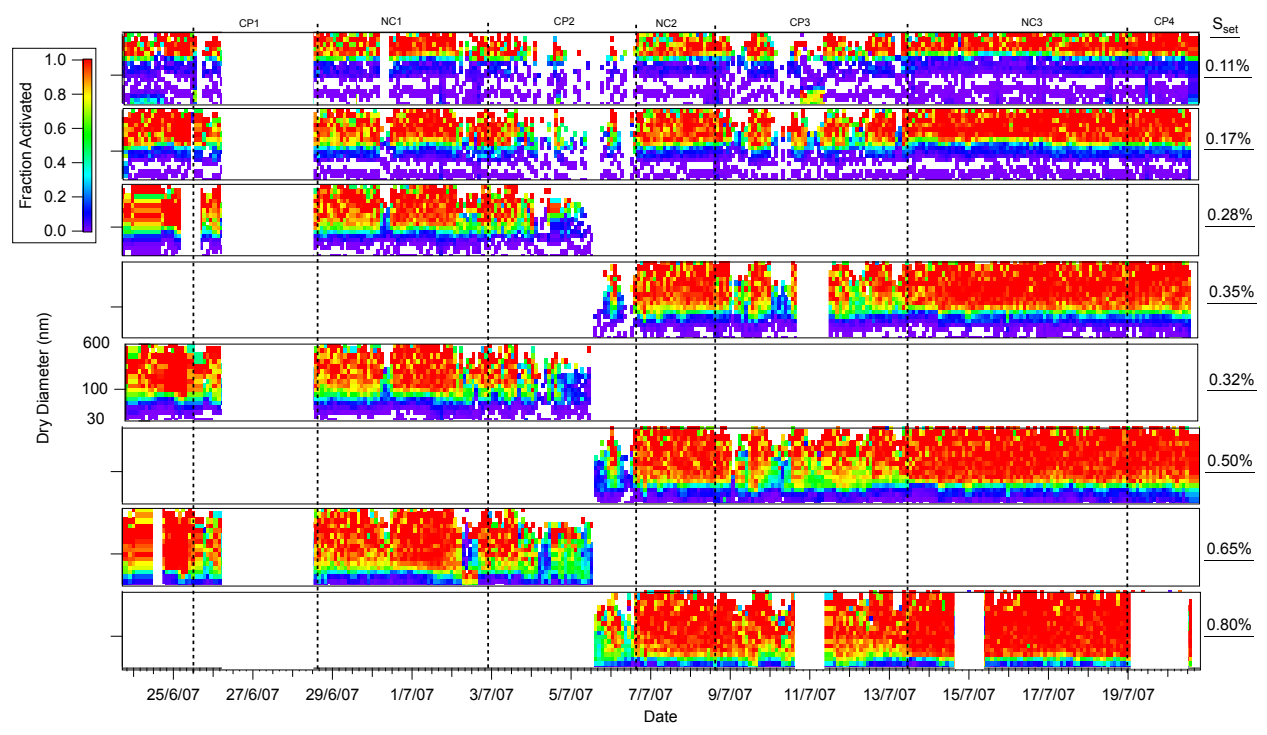

Fig. 2. Fraction of $\mathrm{CCN}$ activated against time, for each supersaturation setting. The fraction of aerosol activated typically increases with dry diameter and supersaturation. The decision was made during CP2 to increase the upper limit of the supersaturation setting ( $\left.S_{\text {set }}\right)$ from $0.65 \%$ to $0.80 \%$, in an attempt to activate more of the aerosol below $100 \mathrm{~nm}$.

increasing supersaturation, until at the highest supersaturation $(0.80 \%)$ almost all particles activate. For the majority of the experiment, each supersaturation could be characterised with a "threshold dry diameter" above which all particles activate.

Though variations throughout the experiment are evident in the activated fraction at each supersaturation (Fig. 2), these do not systematically vary with changes in the ratio of organic to sulphate mass loading (Fig. S3 in the Supplement). However CP2, NC2 and CP3 show some variability in $F_{\mathrm{A}}\left(S, D_{0}\right)$, but these periods are also characterised by low temporal resolution due to low number concentrations (averaged number concentration of less than 5 particles detected at each $D_{0}$ ) between $50 \mathrm{~nm} \leq D_{0} \leq 200 \mathrm{~nm}$. CP3 is characterised by an increase in $F_{\mathrm{A}}\left(S, D_{0}\right)$ across the size distribution, which may be expected as the threshold diameter for activation at a given supersaturation would increase when sampling from within a cloud, as the instrument would then be sampling interstitial particles which have not activated into cloud droplets. In addition, the organic:sulphate ratio (Fig. S3 in the Supplement) is somewhat higher for CP3 than for other cloud periods. The large difference between NC3 and CP4 in terms of the organic:sulphate ratio (10:1 down to $1: 1$, Fig. S3 in the Supplement) is not reflected in the activation ability of the aerosol across the size distribution. This is considered further in Sect. 3.6. It should be noted that size resolved measurements were unavailable at high time resolution and hence any systematic difference may be masked by time or size averaging of the composition.

Figure 3 shows a contour plot of derived $S_{\mathrm{c}, D_{0}}$ for the entire project as described in Sect. 2.3. The supersaturation range $0.11 \%-0.65 \%$ was increased as previously described to $0.11 \%-0.80 \%$. This increased data range typically reduced fitting errors and allowed for the derivation of $S_{\mathrm{c}, D_{0}}$ for smaller particle sizes; illustrated by the inclusion of $S_{\mathrm{c}, D_{0}}$ for $50 \mathrm{~nm}<D_{0}$ (Fig. 3). Whilst some variation in $S_{\mathrm{c}, D_{0}}$ is evident between cloud and no-cloud periods and is consistent with the variation in activated fraction, no systematic difference was found between high and low organic to sulphate periods and $S_{\mathrm{c}, D_{0}}$.

Whilst size resolved measurements were unavailable at high time resolution AMS compositional data was converted from vacuum aerodynamic diameter to mobility diameter using the methods described in DeCarlo et al. (2004) and assuming a typical density for aged organics of $1400 \mathrm{~kg} \mathrm{~m}^{-3}$ (Alfarra et al., 2006; Sjogren et al., 2008) and averaged over the periods of high and low organic to sulphate ratios. Particles over $100 \mathrm{~nm}$ have an increased organic to sulphate content with a peak at around $300 \mathrm{~nm}$ which was above the dry diameter range for HTDMA growth factor measurements and the derivation of critical supersaturation from $\mathrm{CCNc}$ measurements during this experiment (see Fig. S4 in the Supplement). Though $F_{\mathrm{A}}\left(S, D_{0}\right)$ data exists for dry diameters above $300 \mathrm{~nm}$, it is not possible to derive $S_{\mathrm{c}, D_{0}}$ from this data, as the fraction of aerosol activated is almost always over 0.5 at the lowest $S_{\text {set }}$.

\subsection{Reconciliation of the hygroscopicity and droplet activation measurements}

For each dry diameter measured, values of $\kappa$ were calculated by inserting $\overline{\mathrm{GF}}_{D_{0}, 86 \%, \mathrm{c}}$ data into Eq. (2). The derived $\kappa$ value and $\overline{\mathrm{GF}}_{D_{0}, 86 \% \text {, c }}$ were held constant whilst the RH was increased until reaching a maximum, thereby obtaining 


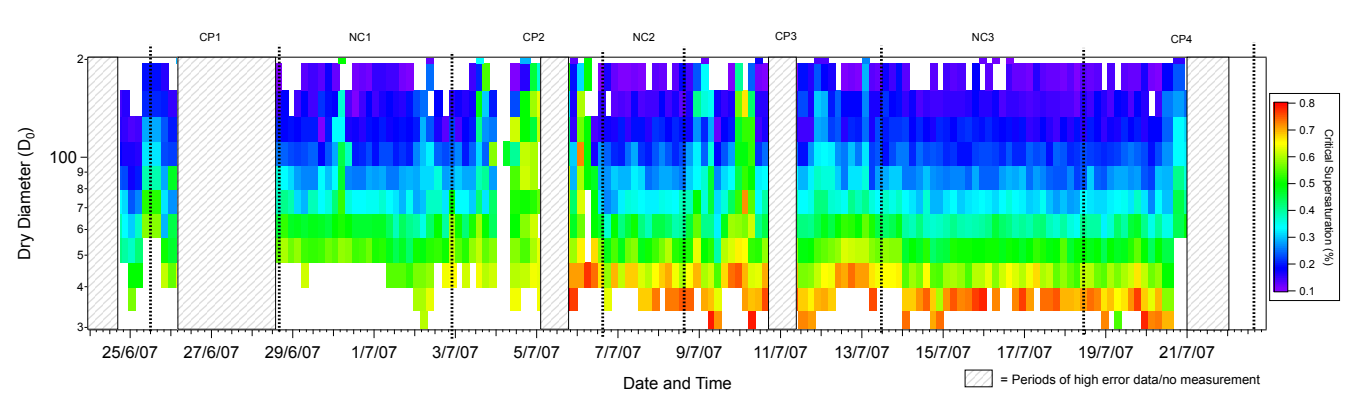

Fig. 3. Time series of $S_{\mathrm{c}, D_{0}}$ for the duration of the experiment. Larger particles typically require less supersaturation to activate and thus have a lower $S_{\mathrm{c}, D_{0}}$. Some variation in $S_{\mathrm{c}, D_{0}}$ is apparent, but does not correspond strongly to changes in the AMS organic:sulphate ratio.

$S_{\mathrm{c}, \mathrm{GF}}$ for each dry diameter. $\kappa$ values were evaluated at a constant assumed surface tension equal to that of pure water $\left(72.5 \mathrm{mNm}^{-1}\right.$ at $\left.298 \mathrm{~K}\right)$ in addition to a range of suppressed $\sigma$ values, neglecting surface-to-bulk partitioning.

$S_{\mathrm{c}, D_{0}}$ was calculated from CCNc data, where possible, in the same fashion as outlined in Sect. 2.3 and in Sect. 1.2 of the Supplement. Calculations of $S_{\mathrm{c}, D_{0}}$ were not possible for $D_{0} \leq 30 \mathrm{~nm}$ or $D_{0} \geq 200 \mathrm{~nm}$ as the critical supersaturation of the aerosol at these sizes was outside of the supersaturation range measured by the instrumentation.

$\overline{\mathrm{GF}}_{D_{0}, 86 \%, \mathrm{c}}$ is plotted against both $S_{\mathrm{c}, \mathrm{GF}}$ (circles) and $S_{\mathrm{c}, D_{0}}$ (crosses) for the size range $20 \mathrm{~nm} \leq D_{0} \leq 200 \mathrm{~nm}$ and is shown in Fig. 4. The box plots in Fig. 4 show the median, 25th and 75th percentiles of the model predicted critical supersaturation, $S_{\mathrm{c}, \mathrm{GF}}$, using the range of mean growth factor measured at the size denoted by colour and the whiskers denote the 10th and 90th percentiles of these predictions. The growth factors for ammonium sulphate are also plotted against their respective $S_{\mathrm{c}, D_{0}}$ for comparison. The coloured circles indicate the predicted $S_{\mathrm{c}, \mathrm{GF}}$ for a given growth factor (and assumed surface tension, $\sigma$ ) for guidance. The crosses represent the measured data pairs of mean growth factor $\overline{\mathrm{GF}}_{D_{0}, 86 \%, \mathrm{c}}$ and $S_{\mathrm{c}, D_{0}}$, with the particle dry diameter represented by its colour. The error bars show the standard error associated with each data point; propagated from primary data quantities as described previously. $\kappa$-Köhler evaluation of HTDMA growth factor and CCNc S-step data assuming a surface tension of water and a temperature of $298 \mathrm{~K}$, shows that for $D_{0}=43 \mathrm{~nm}$ and $85 \mathrm{~nm}$ there is a clear tendency for the model to over-predict $S_{\mathrm{c}, \mathrm{GF}}$, with $S_{\mathrm{c}, D_{0}}$ falling far outside of the box plots beyond the measurement uncertainty, indicating an inability of the model to predict critical supersaturation at these sizes within instrumental uncertainties. At $121 / 127 \mathrm{~nm}$, better agreement between model and measurement is seen, but still with a slight bias towards overpredicting the critical supersaturation. At $D_{0}$ of $174 / 169 \mathrm{~nm}$ similar agreement between model and measurement is seen, but with the bias reversing and underpredicting critical supersaturation. All data points have been ascribed a transparency according to the degree of multimodality in the growth fac- tor distribution using the difference between $\overline{\mathrm{GF}}_{D_{0}, 86 \%, \mathrm{c}}$ and the peak in $p(\mathrm{GF})$ as a qualitative indicator. The solid crosses represent points where these values deviate by less than 5\%, intermediate transparency points for between 5 and $10 \%$ deviation and the most transparent values for points where the mean and peak growth factors deviate by more than $10 \%$. It can be seen that an almost identical trend is followed irrespective of the multimodal nature of the distribution with the best agreement at the largest sizes. So, even when nominally monomodal $\left(\overline{\mathrm{GF}}_{D_{0}, 86 \%, \mathrm{c}}\right.$ within $5 \%$ of the peak in $p(\mathrm{GF})$, reconciliation of sub- and supersaturated measurements at $D_{0}=43 \mathrm{~nm}$ or $85 \mathrm{~nm}$ are not achieved within measurement uncertainty.

Hygroscopicity parameters derived from the sub- and supersaturated water uptake measurements, $\kappa_{S_{\mathrm{c}}}$ and $\kappa_{\mathrm{GF}}$ were calculated (using the surface tension of water, $\sigma=$ $72.5 \mathrm{mNm}^{-1}$, and temperature $298 \mathrm{~K}$ ) and are plotted in Fig. 5 with their associated errors (as described in Sect. 2.6). These data are further tabulated in Tables 2 and 3, where $\kappa$ values have been sectorised according to the organic:sulphate ratio. The greatest discrepancy is observed at smaller particle sizes, with $\kappa_{S_{\mathrm{c}}}$ systematically greater than $\kappa_{\mathrm{GF}}$ and well outside measurement uncertainty. The $\kappa$-values move into closer agreement with increasing size, until at $169 \mathrm{~nm}$ diameter, the average $\kappa_{\mathrm{GF}}$ is slightly greater than the $\kappa_{S_{\mathrm{c}}}$.

No size-dependent systematic difference was found between the HTDMA and $\mathrm{CCNc}$ derived critical supersaturation of particles with different organic to sulphate ratios. Figure 6 shows the HTDMA derived and $\mathrm{CCNc}$ derived critical supersaturations, coloured according to their organic:sulphate ratio. The left panel of Fig. 6 shows that for the larger sizes of $127 \mathrm{~nm}$ and above, the critical supersaturation as predicted from hygroscopicity parameterisation of the HTDMA data is higher during periods of a high organic to sulphate ratio, than when sulphate dominated. However, this is not consistent at all sizes, and when comparing to the critical supersaturations as derived from $\mathrm{CCNc}$ data, there is no clear relationship between particle composition and water affinity. 


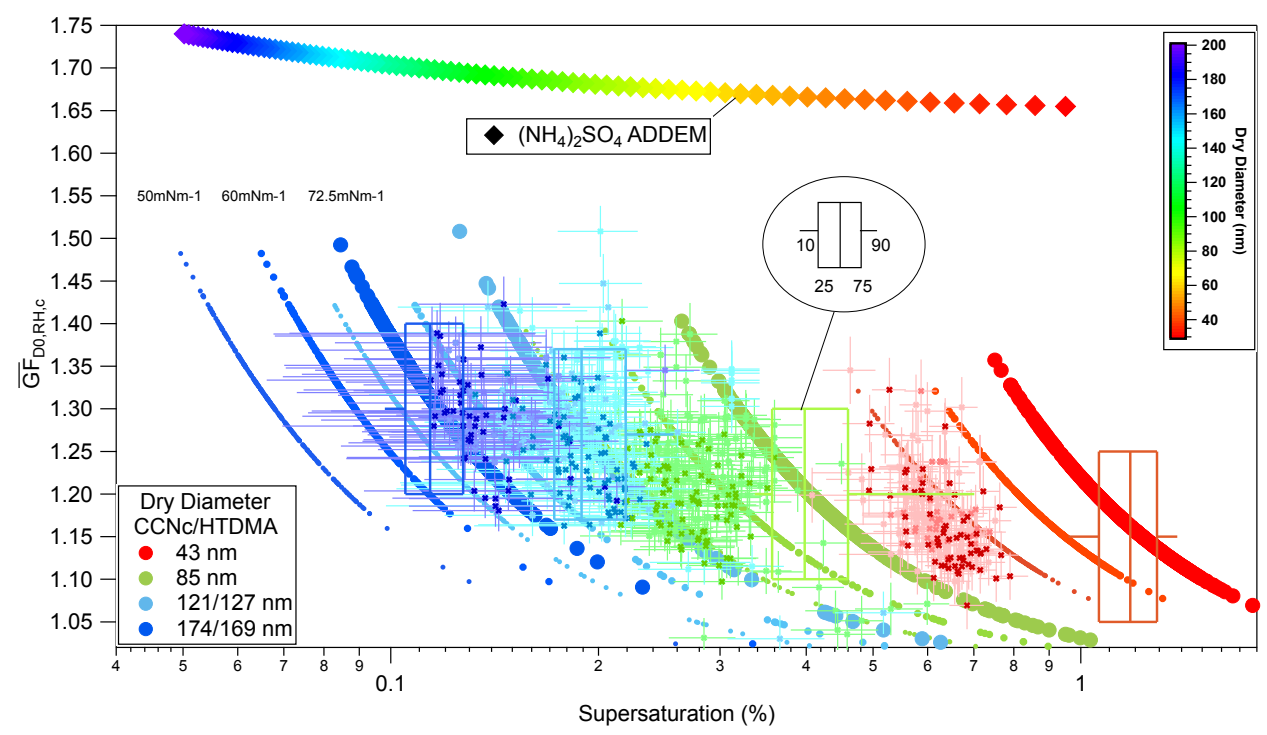

Fig. 4. $\overline{\mathrm{GF}}_{D_{0}, \mathrm{RH}, \mathrm{c}}$ plotted against derived critical supersaturation for HTDMA dry diameters $43 \mathrm{~nm} \leq D_{0} \leq 169 \mathrm{~nm}$. The crosses represent measured data and the circles of increasing diameter represent predictions from the model with three surface tensions; $50 \mathrm{mNm}^{-1}$, $60 \mathrm{mNm}^{-1}$ and $72.5 \mathrm{mNm}^{-1}$ respectively. Error bars are shown in both axis representing the uncertainty in the measured growth factor, and derived $S_{\mathrm{c}, D_{0}}$.
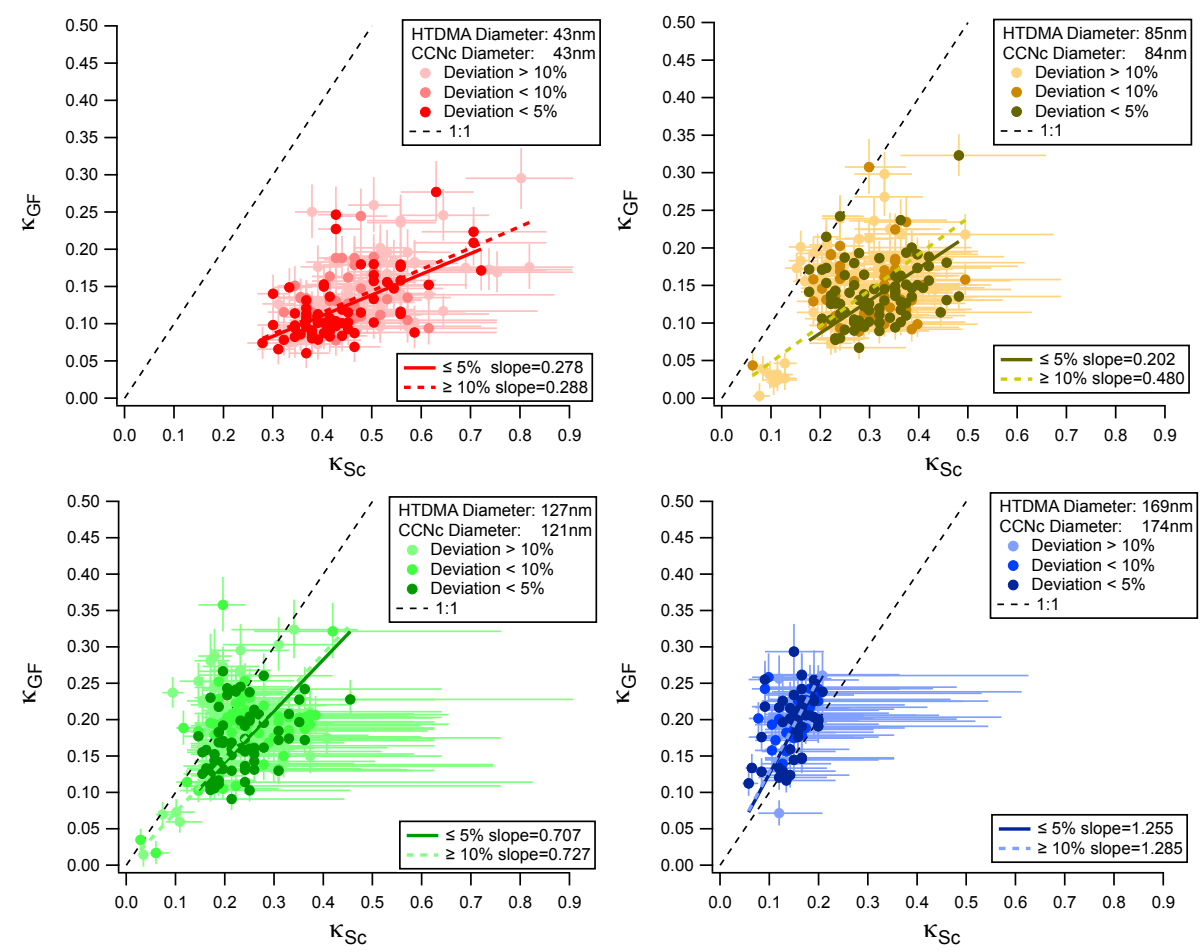

Fig. 5. $\kappa_{\mathrm{GF}}$ plotted against $\kappa_{S_{\mathrm{c}}}$ for the CCN dry diameters closest to those of the measured by the HTDMA. The data is colour weighted according to the proximity of the peak of the growth factor relative to that of the mean growth factor, with the most solid colours representing a deviation below $5 \%$. 

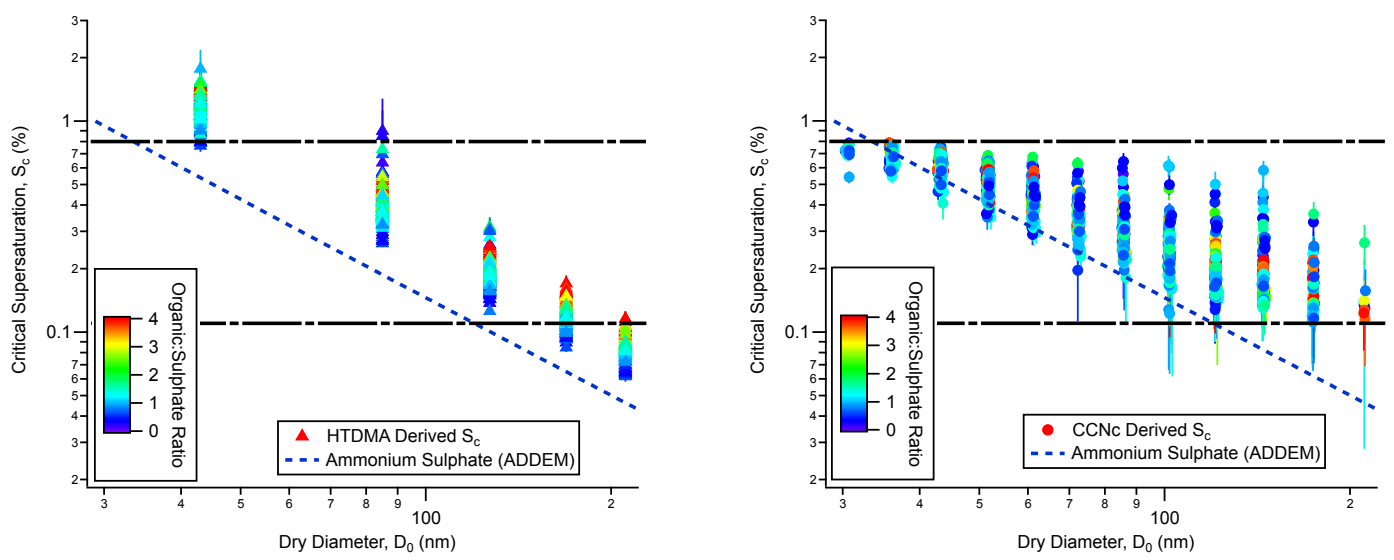

Fig. 6. Left panel: a graph showing $S_{\mathrm{c}, \mathrm{GF}}$ vs. $D_{0}$, coloured according to organic:sulphate ratio. Right panel: a graph showing $S_{\mathrm{c}, D_{0}}$ vs. $D_{0}$, coloured according to organic:sulphate ratio. The black dashed line represents the upper and lower values of the supersaturation setting of the $\mathrm{CCNc}$.

Though the mean $\kappa$ for both CCNc and HTDMA data appear to vary $\left(\bar{\kappa}_{\mathrm{Sc}}=0.292 \pm 0.128, \bar{\kappa}_{\mathrm{GF}}=0.181 \pm 0.056\right)$ with increased relative sulphate contribution, possibly indicating a slightly more hygroscopic aerosol than when the organic:sulphate ratio is high $\left(\bar{\kappa}_{\mathrm{Sc}}=0.283 \pm 0.069, \bar{\kappa}_{\mathrm{GF}}=\right.$ $0.142 \pm 0.036$; Tables 2 and 3 ), the variability of $\kappa$ is too large to draw any firm conclusions. The total aerosol organic fraction is an average across all dry diameters, and the sizeresolved AMS composition campaign average (Fig. S4 in the Supplement) show a markedly higher organic fraction at sizes greater than $100 \mathrm{~nm}$ in both periods of low and high organic fraction. This will most likely contribute to the lack of difference in aerosol hygroscopic growth factor during these periods (Tables 2 and 3), as the relative organic mass fraction at each dry diameter appears to influence their measured hygroscopicity and subsequently derived critical supersaturation, $S_{\kappa, \text { GF }}$ (Fig. 6).

In numerous cases, the mean growth factor either matches the peak value or is too close for an error bar to be visible but there are cases for which the mean growth factor deviates, typically to lower values, from the peak of the hygroscopic mode due to a background of less hygroscopic particles. Even when screening for bimodality, the $\kappa$-Köhler model fails to accurately predict the CCNc derived $S_{\mathrm{c}, D_{0}}$, and the decrease in the discrepancy between model and measurement with larger particle size cannot be solely due to the previously discussed increase in hygroscopic bimodality of the aerosol at larger sizes. It can be seen from the lack of difference between points of varying transparency that the bimodality in aerosol mixing state with respect to growth factor cannot be the only reason for the discrepancy in the HTDMA and $\mathrm{CCNc}$ derived $\kappa$-values.

The aerosol sample airflow is dried through the use of a counterflow nafion drier, before entering both the $\mathrm{CCNc}$ and HTDMA. The RH of the aerosol sample flow after the drying process, will be between the RH before drying (ambi- ent RH) and the RH of the counterflow in the drier (around $\mathrm{RH}=2 \%$ from the compressed air supply). In the drying process, aerosol particles will lose water to the gaseous phase (and thus reduce in size) as the particle airflow attempts to reach equilibrium with the dry sheath air flow. In addition, any volatile or semi-volatile compounds can start to evaporate from the aqueous to the gaseous phase. The emerging aerosol sample flow is therefore a mix of relatively dry particulate matter and a gaseous mixture of water vapour and other semi-volatile compounds (inorganic and organic). Initially, this mixture will be further diluted through the first DMA, but after a few scans (circa $1 \mathrm{~h}$ ), the DMA sheath flow will have also reached equilibrium with the aerosol flow assuming the composition does not change in this time, with both containing similar amounts of components in the gaseous phase. In the HTDMA, after size-selection, the aerosol flow passes through the humidification system, which will grow the particle as water vapour and other gaseous components condense onto the particles. The second DMA (at the RH of the aerosol flow) then sequentially steps through voltages, determining the new particle diameters and thus the growth factor can be calculated. Since the initial drying procedure will not completely dry the particles, a small overestimation of $D_{0}$ will result, hence leading to an underestimation of the measured growth factor even if equilibrium is reached in the humidification section. This is in addition to any further underestimation in growth factor that would result from a perfectly dry aerosol not reaching equilibrium in the humidification section of the instrument (discussed further below).

For example, it has been shown that hygroscopic growth factor measurements of compounds containing nitrate are sensitive to instrument residence time (e.g. Gysel et al., 2007), and generally there was little nitrate seen during the COPS ground measurements. However, there were a few instances later on in the project when higher concentrations of $\mathrm{NO}_{3}^{-}$were observed. The air mass trajectories for 
Table 2. $\kappa$ values for both HTDMA and CCN data, split by an organic:sulphate ratio of $\leq 4: 1 . D_{0}$ is particle dry diameter and $\sigma$ is the standard deviation.

\begin{tabular}{lrrrr}
\hline$D_{0}$ & $\kappa_{S_{\mathrm{c}}}$ & $\sigma$ & $\kappa_{\mathrm{GF}}$ & $\sigma$ \\
\hline $26 \mathrm{~nm}$ & & & 0.137 & 0.046 \\
$43 \mathrm{~nm}$ & 0.464 & 0.099 & 0.129 & 0.045 \\
$85 \mathrm{~nm}$ & 0.269 & 0.100 & 0.147 & 0.052 \\
$121 / 127 \mathrm{~nm}$ & 0.211 & 0.096 & 0.187 & 0.057 \\
$174 / 169 \mathrm{~nm}$ & 0.133 & 0.051 & 0.213 & 0.052 \\
$211 \mathrm{~nm}$ & & & 0.231 & 0.055 \\
\hline
\end{tabular}

these events were different to the other periods (slower wind speeds and thus local influence from nearby valley), and a ZSR calculation showed that the HTDMA was most likely not seeing this $\mathrm{NO}_{3}^{-}$. During COPS, the largest amounts of nitrate were measured on 19 July, incidentally a date marking the end of HTDMA measurements.

Further to the effects of evaporative equilibration in the particle pre-drying section, there are potential kinetic limitations to particle growth. After drying, any particles that are still in the aqueous phase may have different growth rates compared to those in a crystalline solid or glassy state, as a result of differences in the diffusion coefficient in the condensed phase. As the particle initially enters the humidification section, the high RH gaseous mixture within the sheath flow will start to condense onto the surface of the particle, which may not be exactly representative of the composition of the entire particle. As it takes longer for the molecules to diffuse through a solid particle compared to an aqueous one, any compositional influences of water uptake can encounter kinetic limitation to the rate of diffusion of the various compounds within the particle and of the diffusion of water into the particle. That is to say, that the particle will pass through the humidification system before all components of the particle in the solid phase are exposed to water molecules. Such limitation through increased viscosity and reduced diffusion in amorphous solid particles may be thought to be likely in the atmosphere following their discovery in chamber secondary organic aerosol systems Virtanen et al. (2010).

Good et al. (2010b) showed how HTDMA humidification residence time could not be linked directly to aerosol hygroscopicity in multiple chamber experiments involving organic compounds. These finding may indicate that, if nonequilibrium behaviour is responsible for any variability, it would most likely be in the drying section for these particular aerosol systems.

It should be noted that similar drying effects and impacts of semi-volatile component evaporation and condensation can take place in the monodisperse $\mathrm{CCNc}$ configuration used here, providing further potential sources of discrepancies when reconciling HTDMA and $\mathrm{CCNc}$ data.
Table 3. $\kappa$ values for both HTDMA and CCN data, split by an organic:sulphate ratio of $\geq 4: 1 . D_{0}$ is particle dry diameter and $\sigma$ is the standard deviation.

\begin{tabular}{lrrrr}
\hline$D_{0}$ & $\kappa_{S_{\mathrm{c}}}$ & $\sigma$ & $\kappa_{\mathrm{GF}}$ & $\sigma$ \\
\hline $26 \mathrm{~nm}$ & & & 0.139 & 0.036 \\
$43 \mathrm{~nm}$ & 0.430 & 0.104 & 0.084 & 0.042 \\
$85 \mathrm{~nm}$ & 0.203 & 0.118 & 0.090 & 0.057 \\
$121 / 127 \mathrm{~nm}$ & 0.131 & 0.112 & 0.128 & 0.072 \\
$174 / 169 \mathrm{~nm}$ & 0.102 & 0.062 & 0.155 & 0.055 \\
$211 \mathrm{~nm}$ & & & 0.165 & 0.069 \\
\hline
\end{tabular}

\subsection{Number of $\mathrm{CCN}$}

For each supersaturation, assuming internal mixing with respect to CCN activity, the aerosol will have a corresponding threshold dry diameter above which the aerosol particles activate into cloud droplets. It is possible to estimate the maximum $N_{\mathrm{CCN}}$ at the given supersaturation by integrating the DMPS size distribution from the largest diameter bin to this threshold diameter. This provides an upper limit to cloud droplet number, but the competition between droplets for water vapour during the activation and growth process reduces the available supersaturation and cloud droplet number is normally substantially lower. Variation in droplet number is damped by this process and is lower than variation in $\mathrm{CCN}$.

The threshold dry diameter for activation were derived from $\mathrm{CCNc}$ measurement via three methods, two via S-step analysis and one from D-step analysis.

The threshold dry diameter for activation can be calculated from the S-step products $S_{\mathrm{c}, D_{0}}$ and $\kappa_{S_{\mathrm{c}}}$. The first method does not require the hygroscopicity parameter and is found by plotting $S_{\mathrm{c}, D_{0}}-S_{\text {set }}$ against $D_{0}$, defining the intercept (simply where $D_{0}=S_{\text {set }}$ ) as the physical threshold dry diameter for activation. Connecting the two points either side of $S_{\mathrm{c}, D_{0}}-S_{\mathrm{set}}=0$ by a straight line, $D_{\text {thres(Sc) }}$ is determined, as shown in Fig. S5 in the Supplement. A clear benefit of this method is that fewer calculations are performed, thus not increasing the propagated errors further. However, a significant drawback is that this technique only works for interim supersaturations. Alternatively, the threshold diameter for activation can be derived from $\kappa_{S_{\mathrm{c}}}$ through the use of a $\kappa$ lookup table at $1 \mathrm{~nm}$ and $0.01 \kappa$ resolution. The $\kappa$ value is then inserted into Eq. (3) and for a given $S_{\text {set }}$ (effectively $S_{\text {c }}$ ), the threshold dry diameter for activation can be calculated, defined as $D_{\text {thres }(\kappa, \text { Sc })}$. Additionally, using D-step analysis, the threshold dry diameter for activation has been derived by plotting $D_{50, \mathrm{~S}}-D_{0}$ vs. $D_{0}$, where again, the intercept represents the physical threshold dry diameter for activation of the aerosol, denoted $D_{\text {thres }\left(D_{50}\right)}$.

The threshold dry diameter for activation can also be derived from $\kappa_{\mathrm{GF}}$. As there are 7 dry diameters scanned by the HTDMA, each dry diameter has an associated $\overline{\mathrm{GF}}_{D_{0}, \mathrm{RH}, \mathrm{c}}$ and 
thus $\kappa$. A threshold dry diameter is calculated for each $\kappa_{\mathrm{GF}}$ at each $D_{0}$ and $S_{\text {set }}$, and the intercept of $D_{\text {thres }}-D_{0}$ vs. $D_{0}$ defines $D_{\text {thres }(\kappa, \mathrm{GF})}$ at each $S_{\text {set }}$.

The $N_{\mathrm{CCN}}$ calculation is most sensitive to the threshold diameter for activation around the peak of the aerosol size distribution, and is heavily dependent on the position and breadth of this peak. Out of cloud measurements were typically characterised by a monomodal distribution with a peak around $100 \mathrm{~nm}$ and with typical threshold dry activation diameters between $40 \mathrm{~nm}$ and $180 \mathrm{~nm}$, the difference in $N_{\mathrm{CCN}}$ is affected greatly by this mode. Figure 7 a shows the largest difference in single hygroscopicity parameter derived $N_{\mathrm{CCN}}$ occurs at the lowest supersaturation $(0.11 \%)$. Even though the mean difference in the threshold dry diameter is $12 \%$ $\left(D_{\text {thres }(\mathrm{GF})}=182 \mathrm{~nm}, D_{\text {thres }\left(\kappa, S_{\mathrm{c}}\right)}=163 \mathrm{~nm}\right)$, the difference in $N_{\mathrm{CCN}}$ is $40 \%$. For all supersaturations, the disagreement between the predictions of $N_{\mathrm{CCN}}$ is greater than $30 \%$. In contrast, Fig. $7 \mathrm{~b}$ shows the smallest difference in $N_{\mathrm{CCN}}$ between $D_{\text {thres }(\kappa, \mathrm{GF})}$ and $D_{\text {thres }\left(D_{50, \mathrm{~S}}\right)}$ at the lowest supersaturation. This is due to the increased proximity of $D_{\text {thres }(\kappa, \mathrm{GF})}=$ $182 \mathrm{~nm}, D_{\text {thres }\left(D_{50, \mathrm{~s}}\right)}=184 \mathrm{~nm}$. Excluding the measurement at the lowest supersaturation, the results follow a similar pattern as seen in Fig. 7. It can be seen that the discrepancies are usually outside the attributable errors and cannot be easily reconciled.

\section{Discussion}

The degree of success of each reconciliation method is shown in Fig. 7, represented by the slopes of the linear regression fits to the data. The degree of agreement is dependent on the analytical methods for $\mathrm{CCNc}$ data, with the $\kappa$-model showing the weakest overall agreement (most notably at lower supersaturations, as shown by Fig. 5) compared to the better agreement shown for data analysed without invoking the $\kappa$-model. Though it is useful to calculate $\kappa$ values from both $\mathrm{CCNc}$ and HTDMA data for comparison, the more direct analysis (i.e. D-step analysis) allows the threshold dry diameter for activation to be known directly from measurement and is therefore not subjected to model approximations in the same manner. Furthermore, as the threshold diameter for activation cannot be calculated from S-step analysis (i.e. $S_{\mathrm{c}, D_{0}}$ ) data for the highest and lowest supersaturations, the best overall reconciliation between HTDMA data and $\mathrm{CCNc}$ data, are for $\mathrm{CCNc}$ products derived via D-Step analysis, without the use of the $\kappa$-model (i.e. $D_{50, \mathrm{~S}}$ ), as shown by Fig. 7 .

The best overall reconciliation between HTDMA data and $\mathrm{CCNc}$ data, are for the D-step CCNc products derived without the use of the $\kappa$-model (e.g. $D_{50, \mathrm{~S}}$ ), as shown by Fig. 7 . Agreement is strongest most notably at the lowest supersaturation setting; where activation diameters are typically midrange of the DMPS size-distribution (improving fitting statistics). Reconciliation between the HTDMA and CCNc using the hygroscopicity parameter $\kappa$ results in the weakest overall agreement. Figure 5 shows that only for the $127 / 121 \mathrm{~nm}$ and $169 / 174 \mathrm{~nm}$ measurements do values of $\kappa$ approach the 1:1 line; though the error associated with $\kappa_{S_{\mathrm{c}}}$ reduces the confidence in conclusions drawn from this agreement.

However, it must be noted that at both the lowest and highest supersaturations, the number of data points generated from S-step analysis is lower than at intermediate supersaturations as fitting is only successful if $S_{\min } \leq S_{\mathrm{c}} \leq S_{\max }$, and as such the results are biased towards values where critical supersaturation for a threshold diameter for activation is bounded by $S_{\text {set }}$. This is further illustrated by Fig. 6; the predicted critical supersaturations for all sizes, with the exception of $127 \mathrm{~nm}$, have points which fall outside of the $S_{\text {set }}$ range. This creates an artificial floor and ceiling to the critical supersaturation data derived from the $\mathrm{CCNc}$, and even at $121 \mathrm{~nm}$, some of the derivations lead to uncertainty falling outside of this range. This may explain why at $121 / 127 \mathrm{~nm}$ the $\kappa$ values derived from each instrument show best agreement (Fig. 5), and also go some way to explain how the size dependence of $\kappa_{S_{\mathrm{c}}}$ is reversed to that of the HTDMA (Tables 2 and 3 ).

The segregation of the data into single mode (mean growth factor $\leq 5 \%$ of the peak bin), and multi-mode (mean growth factor $\geq 10 \%$ of the peak bin) could not explain the disagreement between the two instruments. No clear influence of mixing state was found when comparing the derived hygroscopicity parameters from both instruments (Fig. 5).

This study was performed with the assumption that the growing cloud droplets have a surface tension equal to that of water $\left(72.5 \mathrm{mNm}^{-1}\right.$ at $\left.298 \mathrm{~K}\right)$ at the point of activation. The model represents the measured critical supersaturations at $174 / 169 \mathrm{~nm}$ well, using a surface tension of $72.5 \mathrm{mNm}^{-1}$ (Fig. 4). In order to bring the model predictions into agreement with the measured $\mathrm{CCN}$ activity for the dry diameters of $121 / 127 \mathrm{~nm}$ and below, surface tensions ranging from $50 \mathrm{mNm}^{-1}$ to $70 \mathrm{mNm}^{-1}$ must be assumed, with the smallest sizes requiring the smallest surface tension. It is not clear that any atmospherically reasonable organic compounds at the concentration found at the point of activation can be responsible for the apparent large surface tension suppressions required to reconcile the data. Furthermore, if the influences of organic compounds on surface tension were important, the critical supersaturation would be lowered with an increasing amount of organic matter, offsetting the increase of $S_{\mathrm{c}, D_{0}}$ expected from a reduction of inorganic matter, potentially leading to a cancellation of effects and no clear relationship.

Surface tensions of multicomponent mixtures are not readily predictable even in bulk solutions (Topping et al., 2005). Bulk to surface partitioning has been postulated as a potentially important phenomena which can increase the predicted critical saturation ratio required for droplet activation through removal of material used to calculate the Raoult term in the Köhler equation (Eq. 1). Neglecting bulk-to-surface partitioning has been shown to result in an underestimation of $S_{\mathrm{c}}$ (Sorjamaa et al., 2004; Kokkola et al., 2006) and that 

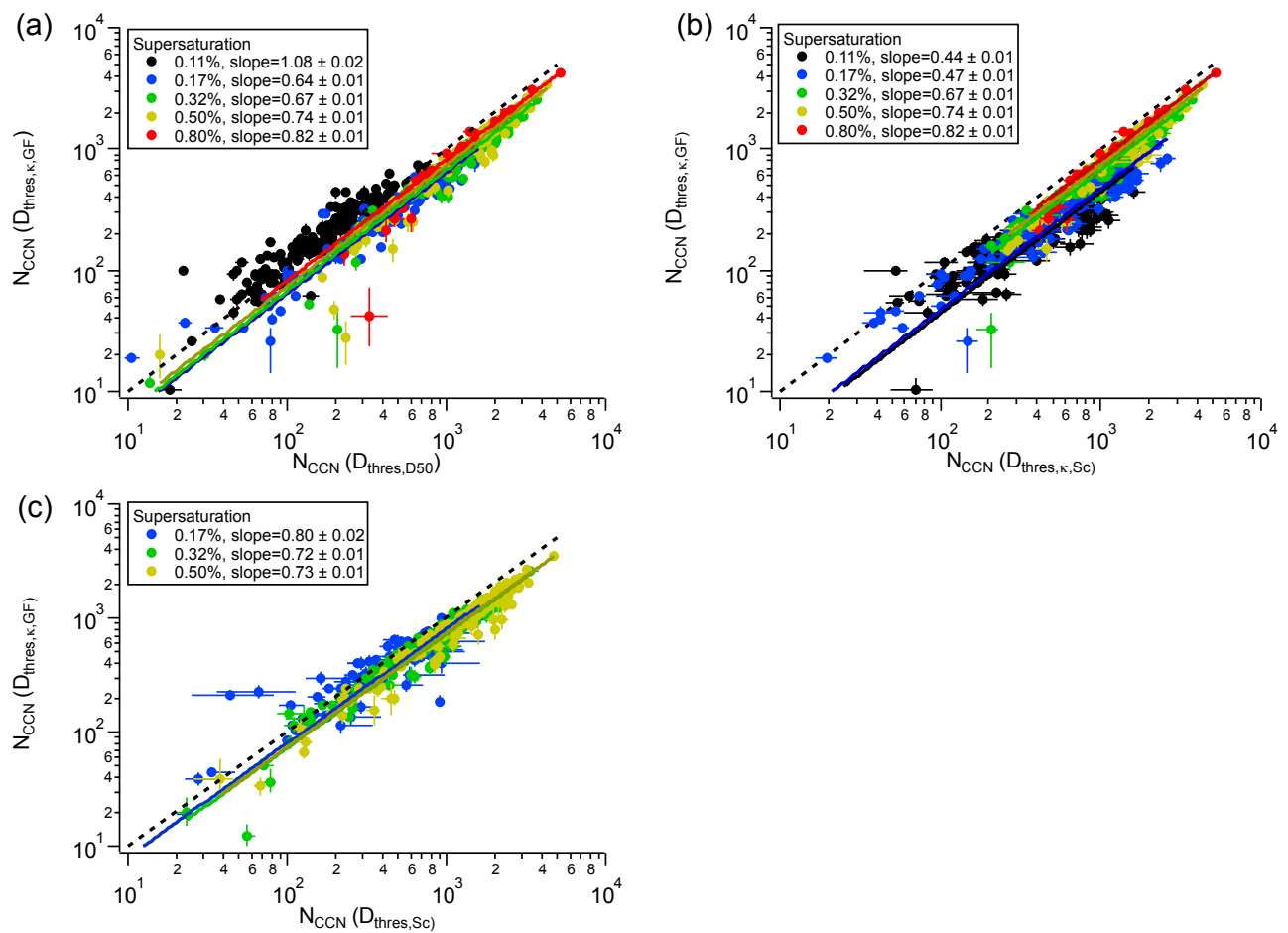

Fig. 7. The number of cloud condensation nuclei $\left(N_{\mathrm{CCN}}\right)$ as predicted from HTDMA derived $\kappa$-Köhler analysis plotted against (a) $N_{\mathrm{CCN}}$ derived from D-step $\left(D_{50, \mathrm{~S}}\right)$ analysis, (b) $N_{\mathrm{CCN}}$ derived from $\kappa_{S_{\mathrm{c}}}$ analysis, (c) $N_{\mathrm{CCN}}$ derived from S-step $\left(S_{\mathrm{c}, D_{0}}\right)$ analysis. Where possible, the calculations were preformed for the five supersaturation settings. The error bars are the upper and lower bounds in $N_{\mathrm{CCN}}$ given as a result of the propagation of errors through the analysis procedure. The best fit lines have been plotted using orthogonal distance regression and are weighted according to error.

the smaller the particle, the greater the effect of surface to bulk partitioning (Sorjamaa et al., 2004). However, for this study all calculations have neglected the partitioning of material between a bulk and surface layer. An overestimation of $S_{\mathrm{c}}$ is seen for all sizes below $121 / 127 \mathrm{~nm}$, above which better agreement is seen between the predicted $S_{\mathrm{c}}$ and measured $S_{\mathrm{c}}$, indicating that if the effects of bulk to surface partitioning were to be included, predicted $S_{\mathrm{c}}$ would further deviate from measured $S_{\mathrm{c}}$.

Segregating the data into periods of high and low sulphate to organic ratio (Fig. S3 in the Supplement and even using size resolved AMS data (Fig. S4 in the Supplement) resulted in no systematic improvement or degradation to the agreement between the predicted and measured data (Fig. 4). Whilst the model leads to better agreement for sizes of 121/127 nm and above (Fig. 4), the reason for the apparent agreement is unclear. The influence of bimodality on the mean growth factor cannot explain the difference between $\kappa_{\mathrm{GF}}$ and $\kappa_{S_{\mathrm{c}}}$, as strongly monomodal aerosol does not conclusively show this to be the reason behind the apparent discrepancy (Fig. 5). As the AMS-derived composition is governed by the composition of relatively large particles, the fact that the hygroscopicity of relatively small particles $(<127 \mathrm{~nm})$ did not correlate with the AMS-derived organic:sulphate ratio is not contradictory. Indeed, in the case of relatively large particles $(>127 \mathrm{~nm})$, some relationship between the HTDMA growth factor data and organic:sulphate ratio was observed (as previously shown in Fig. 6, with HTDMA data represented by $S_{\mathrm{c}, \mathrm{GF}}$ ). It is worth noting that an internally mixed aerosol will appear to be well represented by the mean growth factor, and a spectrum of compositions may appear as one broad mode. This would be lost within the $\mathrm{CCNc}$ data as the resolution of the instrument would not pick out these particles of varied composition. In theory, this broadens the ideal step function in activation space of the $\mathrm{CCNc}$, yet with only 5 supersaturations for each $D_{0}$, the fitted sigmoid function is reasonably broad initially and a spread of compositions would not be resolved in this manner.

The $\kappa$-Köhler model takes a snapshot of the aerosol behaviour at a specific $\mathrm{RH}$, assuming the system to be in equilibrium, and extrapolates these properties to the maximum point in the Köhler curve. The application of the same $\kappa$ assumes the same degree of non-ideality (same activity coefficient of water) at the point of sub-saturated measurement and the critical point of the Köhler curve. Departure from this and from the assumptions of equilibrium (no kinetic limitations to evaporation on drying or growth by recondensation of material at high RH), will manifest themselves as disagreement in reconciliation studies. As previously discussed, the residence time of the sample aerosol on 
drying and humidification within the HTDMA will impact on measured particle growth factor. Similarly for the $\mathrm{CCNc}$, the residence time of the sample aerosol in the drying prior to the DMA size selection may impact on the derived critical supersaturation. Though the role of surface-active compounds at the point of activation remains unclear, we have illustrated that an unrealistically low surface tension of $50 \mathrm{mNm}^{-1}$ is required for HTDMA and $\mathrm{CCNc}$ measurements to agree. It is possible that kinetic limitations to condensation of water in humidification and evaporative departure from equilibrium in drying may substantially contribute to the disagreements shown in Figs. 4, 5 and 7.

\section{Conclusions}

Measurements of aerosol hygroscopic growth, $\mathrm{CCN}$ activity, and composition were made simultaneously and have been used to probe the applicability of a single parameter representation of aerosol water uptake. It was found that changes in the organic:sulphate ratio did result in variations in aerosol hygroscopicity at $86 \%$ RH but no systematic variation in the $\mathrm{CCN}$ activity of the aerosol was found. Periods of measurement conducted "in cloud" were typically characterised by low number concentrations (averaged number concentration of less than 5 particles detected at each $D_{0}$ ), a lower organic:sulphate ratio and a higher hygroscopic mean growth factor. "no-cloud" periods were characterised by higher aerosol concentrations across the size range, an increased organic:sulphate ratio and a lower hygroscopic mean growth factor. Whilst variations in the $\mathrm{CCN}$ fraction are evident they could not be directly linked to changes in composition, in part due to the variations in mixing state of the aerosol during different periods.

Corrected mean growth factors at $86 \% \mathrm{RH}$ as measured by the HTDMA at multiple $D_{0}$ were used to derive the hygroscopicity parameter $\kappa$. The $\kappa$-Köhler model was used to predict both critical supersaturations and threshold diameters for activation from the data. Critical supersaturation was derived as a function of dry diameter by the $\mathrm{CCNc}$ and was compared to the HTDMA $\kappa$-model derived critical supersaturation with varying results. When comparing $\kappa$ derived products from each instrument, the discrepancy appears largest for the most atmospherically relevant supersaturations with the most significant difference being a $56 \%$ difference in $N_{\mathrm{CCN}}$ at the lowest supersaturation $(0.11 \%)$, with higher supersaturations $(0.17-0.80 \%)$ resulting in less difference between prediction and measurement (53\%-18\%), shown in Fig. 7.

$\mathrm{CCNc}$ data was also analysed without the use of the hygroscopicity parameter $\kappa$, but in terms of the threshold dry diameter for activation from both S-step and D-step analyses. The D-step analysis had the best agreement with the HTDMA derived $N_{\mathrm{CCN}}$ at the lowest supersaturation with an $8 \%$ difference, but for the rest of the supersaturation range there was a decreasing over-estimate with supersaturation $(26 \%-$
$18 \%)$. Data which falls closest to the centre of the ranges of dry diameter selection and supersaturation are less susceptible to bias from instrument limitations and as such generated more data points with reduced standard error than those made at the limits of the CCN instrument. From the S-step analysis, the threshold diameter of the aerosol was derived directly from $S_{\mathrm{c}, D_{0}}$ by plotting the intercept of $S_{\mathrm{c}, D_{0}}-S_{\mathrm{set}}$ vs. $S_{\text {set }}$. Whilst this method could only derive $D_{\text {thres,Sc }}$ for the latter-half interim supersaturations of $0.17 \%, 0.32 \%$ and $0.50 \%$, there is only between $20-27 \%$ over estimation when compared to the HTDMA derived $N_{\mathrm{CCN}}$.

Measurement uncertainty has been propagated through to derived products for each calculation presented in the paper. The inclusion and propagation of these errors has allowed an assessment on the reconciliation ability of the instruments to take place. The disagreement between the derived products is far outside instrument uncertainty and as such, attempts have been made to uncover the reason for this disagreement. Mixing state has not resulted in clear, systematic differences between the products and neither has the segregation of the data into periods dominated by sulphate or organic composition. It is clear, is that the predicted critical supersaturation from HTDMA data $\left(S_{\mathrm{c}, \mathrm{GF}}\right)$ will shows best agreement with the derived critical supersaturation from the $\operatorname{CCNc}\left(S_{\mathrm{c}, D_{0}}\right)$ at a dry diameter range that activates mostly within the measured $S_{\text {set }}$ range; a trend that follows for all derived products. Should particles of a given diameter have critical supersaturations that cannot be derived by the $\mathrm{CCNc}$ but can be predicted by the HTDMA, results will surely diverge.

Whilst the $\kappa$-Köhler model has been shown to work for a variety of different compositions (Petters and Kreidenweis, 2007, 2008) and previous $\kappa$-Köhler closure attempts ambient $\mathrm{CCNc}$ and HTDMA measurements have shown agreement to within approximately $20 \%$ (Carrico et al., 2008), it appears not to be the case for the ambient measurements in this study unless surface properties are changed, probably unrealistically. In addition, the inclusion of bulk to surface partitioning would lead to an increased discrepancy between the derived values of $S_{\mathrm{c}}$, illustrating a possible need for caution in the generalised application of this single parameter approximation in ambient atmospheric studies until reasons for the highlighted discrepancies are understood. Obviously the use of $\kappa$ values differing by as much as those derived from our HTDMA and CCN measurements in this study would result in differences in predicted aerosol indirect effects corresponding to the significant difference in $N_{\mathrm{CCN}}$ as reported.

\section{Supplementary material related to this article is available online at: http://www.atmos-chem-phys.net/10/11737/2010/ acp-10-11737-2010-supplement.pdf.}


Acknowledgements. The UK Convective and Orographicallyinduced Precipitation Study (UK-COPS) was funded by the National Environmental Research Council (NERC) (NE/E016200/1) and NERC Ph.D Studentship of Martin Irwin (NER/S/A/2006/14036). The authors wish to thank Michael Flynn and Keith Bower for their assistance in the field.

Edited by: M. C. Facchini

\section{References}

Abdul-Razzak, H. and Ghan, S. J.: Parameterization of the influence of organic surfactants on aerosol activation, J. Geophys. Res.-Atmos., 109, D03205, 10.1029/2003JD004043, 2004.

Albrecht, B.: Aerosols, cloud microphysics, and fractional cloudiness, Science, 245, 1227-1230, 1989.

Alfarra, M. R., Paulsen, D., Gysel, M., Garforth, A. A., Dommen, J., Prévôt, A. S. H., Worsnop, D. R., Baltensperger, U., and Coe, H.: A mass spectrometric study of secondary organic aerosols formed from the photooxidation of anthropogenic and biogenic precursors in a reaction chamber, Atmos. Chem. Phys., 6, 52795293, doi:10.5194/acp-6-5279-2006, 2006.

Andreae, M. and Rosenfeld, D.: Aerosol-cloud-precipitation interactions. Part 1. The nature and sources of cloud-active aerosols, Earth Sci. Rev., 89, 13-41, 2008.

Broekhuizen, K., Chang, R. Y.-W., Leaitch, W. R., Li, S.-M., and Abbatt, J. P. D.: Closure between measured and modeled cloud condensation nuclei (CCN) using size-resolved aerosol compositions in downtown Toronto, Atmos. Chem. Phys., 6, 2513-2524, doi:10.5194/acp-6-2513-2006, 2006.

Carrico, C. M., Petters, M. D., Kreidenweis, S. M., Collett, J. L., Engling, G., and Malm, W. C.: Aerosol hygroscopicity and cloud droplet activation of extracts of filters from biomass burning experiments, J. Geophys. Res., 113, D08206, 10.1029/ 2007JD009274, 2008.

Cubison, M. J., Coe, H., and Gysel, M.: A modified hygroscopic tandem DMA and a data retrieval method based on optimal estimation, J. Aerosol Sci., 36, 846-865, 2005.

Decarlo, P., Slowik, J., Worsnop, D., Davidovits, P., and Jimenez, J.: Particle Morphology and Density Characterization by Combined Mobility and Aerodynamic Diameter Measurements. Part 1: Theory, Aerosol Sci. Technol., 38, 1185-1205, 10.1080/ $027868290903907,2004$.

DeCarlo, P., Kimmel, J., Trimborn, A., Northway, M., Jayne, J., Aiken, A., Gonin, M., Fuhrer, K., Horvath, T., Docherty, K., Worsnop, D., and Jimenez, J. L.: Field-Deployable, HighResolution, Time-of-Flight Aerosol Mass Spectrometer, Anal. Chem., 78, 8281-8289, 2006.

Facchini, M. C., Decesari, S., Mircea, M., Fuzzi, S., and Loglio, G.: Surface tension of atmospheric wet aerosol and cloud/fog droplets in relation to their organic carbon econtent and chemical composition, Atmos. Environ., 33, 4853-4857, 2000.

Forster, P., Ramaswamy, V., Artaxo, P., Berntsen, T., Betts, R., Fahey, D., Haywood, J., Lean, J., Lowe, D., Myhre, G., Nganga, J., Prinn, R., Raga, G., Schulz, M., and Dorland, R. V.: Changes in Atmospheric Constituents and in Radiative Forcing. In: Climate Change 2007: The Physical Science Basis. Contribution of Working Group I to the Fourth Assessment Report of the Intergovernmental Panel on Climate Change, 2007.
Good, N., Coe, H., and McFiggans, G.: Instrumentational operation and analytical methodology for the reconciliation of aerosol water uptake under sub- and supersaturated conditions, Atmos. Meas. Tech., 3, 1241-1254, doi:10.5194/amt-3-12412010, 2010a.

Good, N., Topping, D. O., Duplissy, J., Gysel, M., Meyer, N. K., Metzger, A., Turner, S. F., Baltensperger, U., Ristovski, Z., Weingartner, E., Coe, H., and McFiggans, G.: Widening the gap between measurement and modelling of secondary organic aerosol properties?, Atmos. Chem. Phys., 10, 2577-2593, doi:10.5194/acp-10-2577-2010, 2010b.

Gunthe, S. S., King, S. M., Rose, D., Chen, Q., Roldin, P., Farmer, D. K., Jimenez, J. L., Artaxo, P., Andreae, M. O., Martin, S. T., and Pöschl, U.: Cloud condensation nuclei in pristine tropical rainforest air of Amazonia: size-resolved measurements and modeling of atmospheric aerosol composition and CCN activity, Atmos. Chem. Phys., 9, 7551-7575, doi:10.5194/acp-9-75512009, 2009.

Gysel, M., Crosier, J., Topping, D. O., Whitehead, J. D., Bower, K. N., Cubison, M. J., Williams, P. I., Flynn, M. J., McFiggans, G. B., and Coe, H.: Closure study between chemical composition and hygroscopic growth of aerosol particles during TORCH2, Atmos. Chem. Phys., 7, 6131-6144, doi:10.5194/acp-7-61312007, 2007.

Gysel, M., McFiggans, G., and Coe, H.: Inversion of tandem differential mobility analyser (TDMA) measurements, J. Aerosol Sci., 40, 134-151, 2009.

Hallquist, M., Wenger, J. C., Baltensperger, U., Rudich, Y., Simpson, D., Claeys, M., Dommen, J., Donahue, N. M., George, C., Goldstein, A. H., Hamilton, J. F., Herrmann, H., Hoffmann, T., Iinuma, Y., Jang, M., Jenkin, M. E., Jimenez, J. L., Kiendler-Scharr, A., Maenhaut, W., McFiggans, G., Mentel, Th. F., Monod, A., Prévôt, A. S. H., Seinfeld, J. H., Surratt, J. D., Szmigielski, R., and Wildt, J.: The formation, properties and impact of secondary organic aerosol: current and emerging issues, Atmos. Chem. Phys., 9, 5155-5236, doi:10.5194/acp-95155-2009, 2009.

Haywood, J. and Boucher, O.: Estimates of the direct and indirect radiative forcing due to tropospheric aerosols: A review, Rev. Geophys., 38, 513-543, 2000.

Jones, H. M., Crosier, J., Russell, A., Irwin, M., Flynn, M., Choularton, T., Coe, H., and McFiggans, G.: In-situ aerosol measurements taken during the 2007 COPS field campaign at the Hornisgrinde ground site, Q. J. Roy. Meteorol. Soc., in press, 2010.

Kanakidou, M., Seinfeld, J. H., Pandis, S. N., Barnes, I., Dentener, F. J., Facchini, M. C., Van Dingenen, R., Ervens, B., Nenes, A., Nielsen, C. J., Swietlicki, E., Putaud, J. P., Balkanski, Y., Fuzzi, S., Horth, J., Moortgat, G. K., Winterhalter, R., Myhre, C. E. L., Tsigaridis, K., Vignati, E., Stephanou, E. G., and Wilson, J.: Organic aerosol and global climate modelling: a review, Atmos. Chem. Phys., 5, 1053-1123, doi:10.5194/acp-5-1053-2005, 2005.

Köhler, H.: The nucleus in and the growth of hygroscopic droplets, Trans. Faraday Soc., 32, 1152-1161, 10.1039/TF9363201152, 1936.

Kokkola, H., Sorjamaa, R., Peräniemi, A., Raatikainen, T., and Laaksonen, A.: Cloud formation of particles containing humiclike substances, Geophys. Res. Lett., 33, L10816, 10.1029/ 2006GL026107, 2006. 
Lance, S., Medina, J., Smith, J., and Nenes, A.: Mapping the operation of the DMT continuous flow CCN counter, Aerosol Sci. Technol., 40, 242-254, 2006.

Lohmann, U. and Feichter, J.: Global indirect aerosol effects: a review, Atmos. Chem. Phys., 5, 715-737, doi:10.5194/acp-5-7152005, 2005.

Matthew, B. M., Middlebrook, A., and Onasch, T.: Collection Efficiencies in an Aerodyne Aerosol Mass Spectrometer as a Function of Particle Phase for Laboratory Generated Aerosols, Aerosol Sci. Technol., 42, 884-898, 10.1080/ $02786820802356797,2008$.

McCormick, R. and Ludwig, J.: Climate modification by atmospheric aerosols, Science, 156, 1358-1359, 1967.

McFiggans, G., Alfarra, M., Allan, J., Bower, K., and Coe, H.: Simplification of the representation of the organic component of atmospheric particulates, Faraday Discuss., 130, 341-362, 2005.

McFiggans, G., Artaxo, P., Baltensperger, U., Coe, H., Facchini, M. C., Feingold, G., Fuzzi, S., Gysel, M., Laaksonen, A., Lohmann, U., Mentel, T. F., Murphy, D. M., O’Dowd, C. D., Snider, J. R., and Weingartner, E.: The effect of physical and chemical aerosol properties on warm cloud droplet activation, Atmos. Chem. Phys., 6, 2593-2649, doi:10.5194/acp-6-2593-2006, 2006.

Medina, J., Nenes, A., Sotiropoulou, R., and Cottrell, L.: Cloud condensation nuclei closure during the International Consortium for Atmospheric Research on Transport and Transformation 2004 campaign: Effects of size-resolved composition, J. Geophys. Res, 112, D10S31, 10.1029/2006JD007588, 2007.

Novakov, T. and Penner, J.: Large contribution of organic aerosol to cloud condensation nuclei concentrations, Nature, 365, 823-826, 1993.

Petters, M. D. and Kreidenweis, S. M.: A single parameter representation of hygroscopic growth and cloud condensation nucleus activity, Atmos. Chem. Phys., 7, 1961-1971, doi:10.5194/acp-71961-2007, 2007.

Petters, M. D. and Kreidenweis, S. M.: A single parameter representation of hygroscopic growth and cloud condensation nucleus activity - Part 2: Including solubility, Atmos. Chem. Phys., 8, 6273-6279, doi:10.5194/acp-8-6273-2008, 2008.

Petters, M., Prenni, A. J., Kreidenweis, S. M., and DeMott, P. J.: On Measuring the Critical Diameter of Cloud Condensation Nuclei Using Mobility Selected Aerosol, Aerosol Sci. Technol., 41, 907-913, 2007.

Pruppacher, H. and Klett, J.: Microphysics of Clouds and Precipitation, vol. 18, Kluwer Acad., Norwell, Mass., 1997.

Roberts, G. C. and Nenes, A.: A continuous-flow streamwise thermal-gradient $\mathrm{CCN}$ chamber for atmospheric measurements, Aerosol Sci. Technol., 39, 206-221, 2005.

Rogers, R. R. and Yau, M. K.: A Short Course in Cloud Physics, Butterworth-Heinemann; 3rd edition, January 15, 1989.

Rose, D., Gunthe, S. S., Mikhailov, E., Frank, G. P., Dusek, U., Andreae, M. O., and Pöschl, U.: Calibration and measurement uncertainties of a continuous-flow cloud condensation nuclei counter (DMT-CCNC): CCN activation of ammonium sulfate and sodium chloride aerosol particles in theory and experiment, Atmos. Chem. Phys., 8, 1153-1179, doi:10.5194/acp-8-11532008, 2008.

Saxena, P., Hildemann, L., McMurray, P., and Seinfeld, J. H.: Organics Alter Hygroscopic Behaviour of Atmospheric Particles, J.
Geophys. Res., 100, 18755-18770, 1995.

Seinfeld, J. and Pandis, S.: Atmospheric Chemistry and Physics: From Air Pollution to Climate Change, 1998.

Shulman, M., Jacobson, M., Carlson, R., and Synovec, R.: Dissolution behavior and surface tension effects of organic compounds in nucleating cloud droplets, Geophys. Res. Lett., 23, 277-280, 1996.

Sjogren, S., Gysel, M., Weingartner, E., Alfarra, M. R., Duplissy, J., Cozic, J., Crosier, J., Coe, H., and Baltensperger, U.: Hygroscopicity of the submicrometer aerosol at the high-alpine site Jungfraujoch, $3580 \mathrm{~m}$ a.s.l., Switzerland, Atmos. Chem. Phys., 8, 5715-5729, doi:10.5194/acp-8-5715-2008, 2008.

Sorjamaa, R., Svenningsson, B., Raatikainen, T., Henning, S., Bilde, M., and Laaksonen, A.: The role of surfactants in Khler theory reconsidered, Atmos. Chem. Phys., 4, 2107-2117, doi:10.5194/acp-4-2107-2004, 2004.

Topping, D. O., McFiggans, G. B., and Coe, H.: A curved multicomponent aerosol hygroscopicity model framework: Part 1 - Inorganic compounds, Atmos. Chem. Phys., 5, 1205-1222, doi:10.5194/acp-5-1205-2005, 2005.

Topping, D. O., McFiggans, G. B., Kiss, G., Varga, Z., Facchini, M. C., Decesari, S., and Mircea, M.: Surface tensions of multicomponent mixed inorganic/organic aqueous systems of atmospheric significance: measurements, model predictions and importance for cloud activation predictions, Atmos. Chem. Phys., 7, 2371-2398, doi:10.5194/acp-7-2371-2007, 2007.

Twomey, S.: Influence of Pollution on Shortwave Albedo of Clouds, J. Atmos. Sci., 34, 1149-1152, 1977.

Virtanen, A., Joutsensaari, J., Koop, T., Kannosto, J., Yli-Pirila, P., Leskinen, J., Makela, J. M., Holopainen, J. K., Poeschl, U., Kulmala, M., Worsnop, D. R., and Laaksonen, A.: An amorphous solid state of biogenic secondary organic aerosol particles, Nature, 467, 824-827, 10.1038/nature09455, 2010.

Weingartner, E., Sjögren, S., Cozic, J., Verheggen, B., Baltensberger, U., Alfarra, M. R., Bower, K. N., Flynn, M. J., Gysel, M., and Coe, H.: Hygroscopic properties and chemical composition of aerosol particles at the high alpine site Jungfraujoch, J. Aerosol Sci., 35, S135-S136, 2004.

Wex, H., Stratmann, F., Topping, D., and McFiggans, G.: The Kelvin versus the Raoult Term in the Köhler Equation, J. Atmos. Sci., 65, 4004-4016, 2008.

Wiedensohler, A.: An approximation of the bipolar charge distribution for particles in the submicron size range, J. Aerosol Sci., 19, 387-389, 1987.

Williams, P. I., McFiggans, G., and Gallagher, M. W.: Latitudinal aerosol size distribution variation in the Eastern Atlantic Ocean measured aboard the FS-Polarstern, Atmos. Chem. Phys., 7, 2563-2573, doi:10.5194/acp-7-2563-2007, 2007.

Wulfmeyer, V, Behrendt, A., Bauer, H., Kottmeier, C., Corsmeier, U., Blyth, A., Craig, G., Schumann, U., Hagen, M., Crewell, S., Girolamo, P. D., Flamant, C., Miller, M., Montani, A., Mobbs, S., Richard, E., Rotach, M., Arpagaus, M., Russchenberg, H., Schlüssel, P., König, M., Gärtner, V., Steinacker, R., Dorninger, M., Turner, D., Weckwerth, T., Hense, A., and Simmer, C.: A research and Development Project of the World Weather research Program for Improving Quantitative Precipitation Forecasting in Low-Mountain regions, American Meteorological Society, 89, 1477-1486, 2008. 